\title{
Is Structural Separation of Incumbent Local Exchange Carriers Necessary for Competition?
}

\author{
Robert W. Crandall ${ }^{\dagger}$ \\ J. Gregory Sidak ${ }^{\dagger \dagger}$
}

Although competitive local exchange carriers ("CLECs") collectively have gained considerable market share since the passage of the Telecommunications Act of 1996, many entrants into local telecommunications have stumbled or failed. Some argue that competitive local telephony will eventuate only if the incumbent local exchange carriers ("ILECs") place their wholesale and retail operations in structurally separate subsidiaries. By mid-2001, several states began proceedings on mandatory structural separation, and influential members of Congress introduced legislation mandating structural separation. In this Article, we analyze, and reject as unpersuasive, the putative benefits of mandatory structural separation. Such regulatory intervention is unnecessary to prevent discrimination against unaffiliated retailers of telecommunications services. Nor would mandatory structural separation lower wholesale discounts or increase the CLECs' market share. Plausible hypotheses for the CLECs' problems do not require the assumption of anticompetitive behavior by the ILECs. Apart from producing no discernable benefits to consumers, mandatory structural separation would entail a substantial social cost in terms of forgone coordination of investment and production and forgone economies of scope. Moreover, mandatory structural separation would harm consumer welfare and reduce resources for investment by facilitating an anticompetitive strategy by the ILECs' largest rivals to raise the ILECs' costs of providing local telecommunications services. Policy makers should reject proposals for mandatory structural separation of the ILECs.

Introduction

I. AT\&T's Hypothesis for Failing CLECs and Its Call for Mandatory Structural Separation.

$\dagger \quad$ Senior Fellow, The Brookings Institution.

t† F.K. Weyerhaeuser Fellow in Law and Economics Emeritus, American Enterprise Institute for Public Policy Research. The authors have consulted to, and testified on behalf of, incumbent local exchange carriers and the United States Telecom Association in numerous regulatory proceedings in the United States and other nations over the course of many years. The views expressed here are solely those of the authors and not those of the Brookings Institution or the American Enterprise Institute, neither of which takes institutional positions on specific legislative, regulatory, adjudicatory, or executive matters. 
A. The Allegation that Anticompetitive Behavior by the ILECS Caused the CLECs to Fail.

B. The Argument that Mandatory Structural Separation Would "Level the Playing Field" Between Nonaffiliated Local Retail Providers and the ILECS ..............................................342

1. CompTel's Idealized Vision of Structural Separation.......342

2. The OECD's Idealized Vision of Structural Separation...343

C. Structural Separation in Practice ............................................346

1. The Pennsylvania PUC's Experience ...............................346

2. The Florida PSC's Experience .........................................349

D. The Purported Merits of Mandatory Structural Separation ....351

E. Japan's Cautious Evaluation of Structural Separation ............352

II. A Critique of AT\&T's Hypothesis and Its Proposed Remedy ..........354

A. The Inability of Allegedly Anticompetitive Practices to Explain Market and Regulatory Phenomena ..........................354

1. The Steady Increase in CLECs' Market Share ..................354

2. Regulatory Approval for RBOC Entry into LongDistance Services ..........................................................359

3. Other Factors that Suggest Greater Competition...............360

B. The Inefficiency of Mandatory Structural Separation .................364

1. The Coordination of Investment and Production

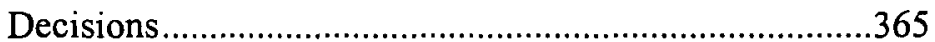

2. Accountability for Product Quality ..................................368

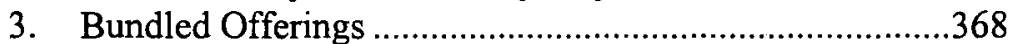

4. The Division of Indivisible Assets ..................................369

5. Enforcement Costs...........................................................370

C. The Inefficacy of Mandatory Structural Separation..................371

1. The Absence of Systematic Evidence of Discrimination .372

2. The Ability of Behavioral Restraints to Prevent

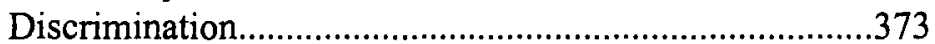

3. The Inability of Mandatory Structural Separation to Lower Wholesale Discounts .............................................373

4. The Unsatisfactory or Inconclusive Experience with Structural Separation..........................................................375

III. The Probable Cause of CLEC Failures ..........................................389

A. Faulty Business Strategies ...................................................390

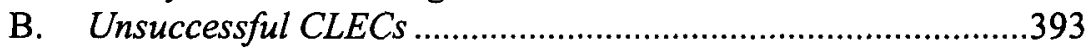

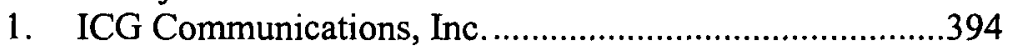

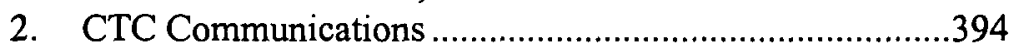

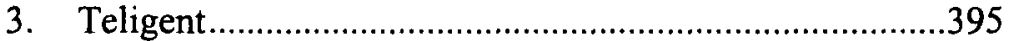

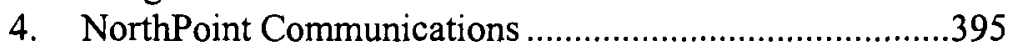


5. Focal Communications

C. The Effect on Local Competition of Elimination of Unbundling Requirements.

D. Assessment of the CLEC Sector

IV. The Ulterior Motivation for Advocating Mandatory Structural Separation: Raising Rivals' Costs

A. Mandatory Structural Separation and the Retail PriceSqueeze Rule.

B. Strategic Exploitation of Jurisdictional Separation of Common Costs .405

Conclusion. 409

Introduction

When Congress passed the Telecommunications Act of 1996, it said that the legislation's purpose was to "promote competition and reduce regulation in order to secure lower prices and higher quality services for American telecommunications consumers and encourage the rapid deployment of new telecommunications technologies."1 Half a dozen years have now passed. The vision held by some of a radically different market structure for local telecommunications has thus far failed to materialize. Collectively, competitive local exchange carriers ("CLECs") are gaining market share and accounted for $9.0 \%$ of switched-access lines in the United States as of June 30, 2001. ${ }^{2}$ The New York Public Service Commission has reported that as of December 31, 2000, CLECs supplied 2.9 million lines in that state, for a market share of $20.9 \%$. $^{3}$ For the first time, more CLEC lines (52\%) served residences than businesses $(48 \%)$ in New York. ${ }^{4}$ Still, many entrants into the market for telecommunications have gone bankrupt or lost a substantial fraction of their market capitalization, and many telecommunications carriers now face substantial debt burdens. ${ }^{5}$ Between the fourth quarter of 1999 and the fourth quarter of

\footnotetext{
1 Telecommunications Act of 1996, Pub. L. No. 104-104, preamble, 110 Stat. 56.

2 Federal Communications Commission, Local Telephone Competition: Status as of June 30, 2001 (2002) [hereinafter Local Telephone Competition Update].

3 New York State Public Service Commission, Analysis of Local Exchange Service Competition in New York State 3 (Aug. 2001), available at http://www.dps.state.ny.us/telecom/ telanalysis.htm.

$4 \quad I d$. at 4.

5 See, e.g., Drowning in Glass: The Fibre-Optic Glut: Can You Have too Much of a Good Thing? The History of Technology Says Not, but that was Before the Fibre-Optic Bubble, ECONOMIST, Mar. 24, 2001, at *1 (documenting ratio of debt to market capitalization); Gregory Zuckerman \& Deborah Soloman, Telecom Debt Debacle Could Lead to Losses of Historic Proportions, WALL ST. J.,
} 
2001, at least twelve publicly traded CLECs experienced negative growth in earnings, and many filed for Chapter 11 bankruptcy protection, including WinStar, Northpoint, ICG, Covad, and Net2000. ${ }^{6}$

The competing explanations for the difficulties encountered by many CLECs are numerous. In particular, however, some argue that the current regulatory strategy (or the current path of "managed competition" adopted in lieu of true deregulation ${ }^{7}$ ) is not enough and that competitive local telephony will eventuate only if regulators require the incumbent local exchange carriers ("ILECs") to place their wholesale and retail operations in structurally separate subsidiaries. In February 2001, the chairman of AT\&T, C. Michael Armstrong, publicly advocated such intervention by state or federal regulators or by Congress. ${ }^{8}$ By the summer of 2001, regulators in Pennsylvania, New Jersey, and Florida had considered or begun proceedings on the subject, ${ }^{9}$ and Senator Ernest F. Hollings, chairman of the Senate Commerce Committee, had introduced the Telecommunications Competition Enforcement Act of 2001, a bill that would mandate structural separation of the ILECs. ${ }^{10}$

Structural separation is also becoming an issue of international importance. For example, in Japan, the new CLECs are demanding the full structural separation of Nippon Telegraph and Telephone Corp. ("NTT") even though the firm's mobile services operations were divested in 1992 and its remaining operations were forcibly reorganized under a holding

May 11, 2001, at A1. Manufacturers of telecommunications equipment have suffered similar losses in market value. Two of the largest suppliers, Alcatel and Lucent, explored plans to merge in May 2001 due to the downtum in demand for telecommunications equipment, but they ultimately rejected a merger. See Nikhil Deogun, et al., Alcatel Nears Deal to Acquire Lucent For About $\$ 23.5$ Billion in Stock, WALL ST. J., May 29, 2001, at A3; Greg Schneider \& William Drozdiak, Lucent Merger Talks Collapse, WASH. POST, May 30, 2001, at E1.

6 See, e.g., GST TELECOMMUNICATIONS INC., 1999 SEC FORM 10-K (Mar. 29, 2000); Yuki Noguchi, Rising Up to the Challenge: 4 Upstart Telecom Companies Are Picking Up Where the Bells Left Off, WASH. POST, Feb. 28, 2001, at G14; Covad Makes Filing in Bankruptcy Court in Bondholder Deal, WALL ST. J., Aug. 16, 2001 , at B2.

7 Managed competition, sometimes called "asymmetric regulation" or "dominant carrier regulation," places larger relative regulatory obligations on the incumbent firm. See J. Gregory Sidak \& Daniel F. Spulber, Deregulation and Managed Competition in Network Industries, 15 YALE J. ON REG. 117 (1998); Robert W. Crandall, Managed Competition in U.S. Telecommunications (AEIBrookings Joint Center Working Paper No. 99-01, Mar. 1999).

8 Speech of C. Michael Armstrong, National Press Club, Feb. 7, 2001, at http://www.att.com/speeches/item/0,1363,3662,00.html.

9 Global Order of Structural Separation of Bell Atlantic-Pennsylvania, Inc., Retail and Wholesale Operations, Dkt. Nos. P-00991648, P-00991649, at 222, Pa. Pub. Util. Comm'n, Sept. 30, 1999 [hereinafter Pennsylvania Global Order]; Petition of AT\&T Communications of the Southern States, Inc., TCG South Florida, and MediaOne Florida Telecommunications, Inc., for Structural Separation of BellSouth Telecommunications, Inc., Dkt. No. 010345-TP, Fla. Pub. Serv. Comm'n, Mar. 21, 2001; Request for Proposal to Conduct a Comprehensive Review of the Financial Integrity of Verizon New Jersey, Dkt. No. TO01020095, N.J. Bd. Pub. Util, May 8, 2001.

10 S. 1364, 107th Cong. (2001). 
company structure in July $1999 .{ }^{11}$ Under the terms of the governmentmandated restructuring, NTT's long distance service became NTT Communications Corp. and its local service was divided to form the regional carriers NTT East and NTT West. ${ }^{12}$ NTT remained as the holding company of its newly-created subsidiaries, but was prevented from crosssubsidizing the losses of any subsidiary with earnings from other subsidiaries. ${ }^{13}$ Now, NTT faces the possibility of full divestiture, despite the fact that the regional carriers had negative earnings in $2001 .^{14}$

Part I examines AT\&T's hypothesis for failing CLECs and its proposal for mandatory structural separation. According to AT\&T, anticompetitive behavior by the ILECs caused the CLECs to fail. Ostensibly to prevent discrimination against nonaffiliated retailers of local service, AT\&T and some other CLECs urge regulators to separate structurally the ILECs into wholesale and retail companies. According to its proponents, structural separation would "level the playing field"15 between nonaffiliated local retail providers and the ILECs.

In Part II, we critique AT\&T's diagnosis of local competition and its accompanying structural solution. Anticompetitive practices cannot explain certain market and regulatory phenomena. Despite allegations of anticompetitive practices by the ILECs, some CLECs are thriving. Indeed, we demonstrate that CLECs' market share has steadily increased between 1998 and 2002. Moreover, during the same time period, state regulators have approved the entry of regional Bell operating companies ("RBOCs") into long-distance services-an event that is not consistent with anticompetitive behavior. Next, we argue that mandatory structural separation is inefficient. Its likely costs would exceed any purported benefits. In particular, we examine several potential efficiency gains associated with vertical integration, including, among others, the coordination of investment and production decisions, accountability for product quality, and the ability to make bundled service offerings.

11 Glossary of Deregulation, NIKKEINET INTERACTIVE, at http://www.nni.nikkei.co.jp/ (Mar. 16, 2002) [hereinafter Glossary of Deregulation].

12 Id.; ORGANIZATION FOR ECONOMIC COOPERATION AND DEVELOPMENT, STRUCTURAL. SEPARATION IN REgulated INDUSTRIES, ๆ 160, tbl.A-8 (Apr. 10, 2001) (noting that NTT was forced to divest its mobile operation to form NTT DoCoMo, although NTT retained $94.7 \%$ ownership in the new company at the time of divestiture) [hereinafter OECD].

13 Glossary of Deregulation, supra note 11.

14 Id.

15 The "level playing field" is the most overused and ambiguous cliche in the regulation of network industries (if not all economic policy). To the extent that the cliché connotes the assurance of an equality of outcomes among rival firms, we thoroughly reject it as a proper goal of regulation. The cliché is a useful and proper goal of regulation only to the extent that it focuses on consumer welfare (not competitor welfare) and connotes the elimination of regulatory barriers that would otherwise deny certain rivals an equal opportunity to compete. 
Mandatory structural separation would jeopardize each of these efficiencies. We conclude Part II by explaining why mandatory structural separation is not an efficacious remedy under any diagnosis of the CLECs' problems. First, there is no systematic evidence of discrimination. Second, behavioral restraints could prevent discrimination. Third, mandatory structural separation would not lower wholesale discounts to CLECs. Fourth, the experience with structural separation in several other contexts has been unsatisfactory or inconclusive.

In Part III of this Article, we suggest that faulty business strategies are to blame for many CLEC failures. Our hypothesis is consistent with empirical evidence that, despite the massive shakeout in the telecommunications sector, some CLECs have actually prospered. Next, we provide anecdotal and empirical evidence that supports our hypothesis. In particular, we review the business strategies of several CLECs and then correlate those strategies with success or failure. Entrants that deliberately built their own networks, carefully analyzing competition and consumer demand before entry, were able to increase revenues and continue to attract capital. An overly generous unbundling regime that rewards CLECs for deferring investment might be at the root of the CLECs' problems.

Part IV explains how mandatory structural separation can serve an ulterior motive: It can advance an anticompetitive strategy of AT\&T and others to raise the ILECs' costs of providing local telecommunications services. This strategy of raising rivals' costs would ultimately increase costs for consumers and reduce investment.

We conclude with the recommendation that policy makers reject proposals for mandatory structural separation of the ILECs.

I. AT\&T's Hypothesis for Failing CLECs and Its Call for Mandatory Structural Separation

The phrase "structural separation" has come to have many meanings. Different meanings of the term, however, have different policy implications. In general, there are three different understandings of structural separation. The first type is the divestiture of the retail service division from the wholesale network division. Under the second form of structural separation, one company owns and operates the telecommunications network while other companies actually provide the service to end users. The third form, functional separation, requires the ILEC to form separate divisions that interact at arm's length. We explore the meaning of mandatory structural separation and lay out its purported merits. 
AT\&T and CompTel, a trade association of CLECs, have advanced a hypothesis to explain the failure of several CLECs. In the Sections that follow, we explain their hypothesis and their proposed remedymandatory structural separation of the ILECs.

\section{A. The Allegation that Anticompetitive Behavior by the ILECs Caused the CLECS to Fail}

AT\&T and several CLEC associations blame the failure of several CLECs on allegedly anticompetitive practices of the ILECs. In a July 2001 study commissioned by CompTel, the trade association attempted to link the industry shakeout with the self-interested practices of the ILECs:

Opening the local network to competitors is unquestionably complex, but the magnitude of the problem has grown exponentially because the entity responsible for implementing nondiscriminatory access is itself the sole beneficiary of the exclusive access that exists today. The past five years have shown that attempting to overcome these incentives through a series of regulatory orders-reached only at the conclusion of protracted and expensive litigation-is not producing the necessary results.

Indeed, the competitive sector of the telecommunications industry is in serious jeopardy as several CLECs have declared bankruptcy, missed revenue targets, curtailed entry into new markets and laid off employees. Moreover, these impacts are not limited to CLECs (and their customers); these effects are also being felt upstream with the manufacturers of telecommunications equipment themselves. ${ }^{16}$

CompTel also pointed to the ILECs' failure to enter out-of-territory local markets as "the most telling evidence that substantial barriers remain to local competition."17

The specific allegations of anticompetitive behavior by ILECs fall into two broad categories: preferential treatment by the ILEC of its own retail operations when providing network access, and insufficient discounts offered by the ILEC when selling its wholesale services to the CLECs. AT\&T has argued that the failure of CLECs and their problems in gaining market share in local telephony arise from discriminatory behavior by the ILECs. Some CLECs have blamed their lack of success on their

16 COMPETITIVE TElecommunications ASSOCIATION, StRUCTURAL INCENTIVES: ThE SIMPLER, MORE EFFICIENT PATH TO LOCAL COMPETITION (presented at the Nat'l Ass'n of Regulatory Util. Comm'rs Summer Meeting, July 14, 2001), at 4 [hereinafter COMPTEL STUDY].

$17 \quad$ Id. at 5. 
inability to lease facilities from the ILECs in a timely fashion. These CLECs have alleged "delaying tactics, inaccurate information and pricing tricks" of the ILECs' wholesale divisions against unaffiliated retail providers. ${ }^{18} \mathrm{Mr}$. Armstrong of AT\&T has blamed the ILECs for not providing the CLECs with "adequate system support" and for mishandling competitive requests. ${ }^{19}$ AT\&T and other carriers have argued that mandatory structural separation of the ILECs is necessary to give the CLECs nondiscriminatory access to the ILECs' computer systems that manage customer data. ${ }^{20}$

\section{B. The Argument that Mandatory Structural Separation Would "Level the Playing Field" Between Nonaffiliated Local Retail Providers and the ILECS}

Seizing on the evidence of CLEC failures, AT\&T and the CLEC industry associations have petitioned state public utility commissions ("PUCs") to mandate structural separation of the ILECs in the name of preventing their allegedly anticompetitive behavior against the CLECs. ${ }^{21}$

\section{CompTel's Idealized Vision of Structural Separation}

According to CompTel, the fundamental notion of mandatory structural separation is "to place the ILEC's retail operations in the shoes of a CLEC-ordering UNEs, establishing customer accounts, and incurring UNE charges just like any other provider." ${ }^{, 2}$ To achieve this objective, CompTel proposes two basic structural conditions:

First, the Retail Company must use exactly the same operational interfaces as other CLECs, standing as a distinct entity-ordering interconnection, UNEs (and UNE combinations) and collocation services from the Wholesale Company, and constrained by the same systems and policies as any other carrier. In this way, any concern that the incumbent would impose complex, costly and inefficient systems on entrants would be greatly reduced because the incumbent's own retail operations would

\footnotetext{
$10 \mathrm{~A}$.

18 Competition in Local Phone Service Fails to Connect, USA TODAY, Feb. 7, 2001, at

19 Id.

20 AT\&T Seeks Structural Separation of Verizon in New Jersey, TELECOMM. REP. DAILY, Feb. 27, 200 l.

21 See, e.g., Initial Comments of AT\&T Communications of Pennsylvania Inc., Joint Petition to Adopt Settlement Agreement and to Terminate the Proceeding, Dkt. No. N00001353F0002, Pa. Pub. Util. Comm'n, Jan. 2, 2001.

22 COMPTEL STUDY, supra note 16, at 6.
} 
be subjected to the same inefficiencies. Second, the retail affiliate must view its UNE-payments to the wholesale entity in the same way as any entrant-as actual outlays that affect its profitability. To achieve this latter condition, the retail entity cannot be a wholly-owned affiliate of the parent. Under a structure where both entities are wholly-owned by the parent, any payment by one affiliate to the other is an economic fiction. Because shareholders only judge management by its consolidated performance, it is irrelevant what one affiliate "pays" another. ${ }^{23}$

Mandatory structural separation would require "sufficient independent ownership" of the retail and wholesale companies. ${ }^{24}$ CompTel outlines the ownership structure of the retail affiliate, which includes the creation of a separate publicly traded stock for the retail affiliate and, of course, a distinct name.

In addition to the above structural conditions, CompTel would add two conduct remedies for mandatory structural separation to work. First, the retail affiliate would initially be established without customers and would be dependent upon the same provisioning systems to obtain customers as any other CLEC. ${ }^{25}$ Because of the implementation process, the wholesale company would continue to serve the embedded base on a transitional basis. Second, the ILEC would not initiate service to any new account, transfer service to a different location, or introduce any new service. $^{26}$

\section{The OECD's Idealized Vision of Structural Separation}

In April 2001, the Organization for Economic Cooperation and Development ("OECD") issued a report entitled, Structural Separation in Regulated Industries. ${ }^{27}$ The report focused on structural methods for improving competition in industries supplied by a regulated monopolist. The OECD found vertical integration by regulated monopolists to be a problem because those entities "may have both the incentive and the ability to restrict competition in the competitive component . . . by controlling the terms and conditions at which rival firms in the competitive component have access to the non-competitive component." 28

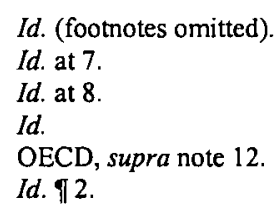


Applied to the market for local telecommunications services, the OECD considered wholesale services to be the "non-competitive component" and retail services to be the "competitive component." The OECD proposed six remedies to maintain competition in the competitive component. Applied to local telephony, the six remedies would take the following form:

1. Conduct remedies: restrictions on the operations of the ILEC's retail unit

2. Equal access: promotion of fair access to the wholesale products and services of an ILEC

3. Ownership separation: structural separation of the ILEC's wholesale and retail divisions

4. "Club" or joint ownership: shared ownership of the ILEC's wholesale division by competitive retail firms

5. Operational separation: transfer of control of the ILEC's wholesale operations to an independent entity

6. Horizontal divestiture: separation of the ILEC into smaller, vertically integrated carriers ${ }^{29}$

Of the six remedies, the first two are behavioral remedies and the last four are structural remedies. Some of the structural remedies are mutually exclusive.

The OECD incorrectly believed that structural remedies are simple while behavioral remedies require more regulation. Thus, when it specifically addressed the telecommunications industry in its report, the OECD examined only the ownership-separation and horizontal-divestiture options. Moreover, the OECD did not provide a critical analysis of these remedies but instead, listed member countries that have implemented various forms of structural separation.

The OECD favored ownership separation and horizontal divestiture for telecommunications carriers because it believed that such separation would bring the ILEC's incentives into alignment with a non-integrated carrier, promote competitiveness, and "alleviate" the need for regulation. ${ }^{30}$ For this reason, the OECD gave special attention to the separation of local fixed-wire service from mobile service and broadband service. ${ }^{31}$ Although the OECD argued that ownership separation would promote entry and innovation into the competitive market, it also admitted that "[i]mportant

29 Id. $\uparrow 4$.

$30 \quad$ Id. $\ 23$

31 Id. ๆT 158-67. 
innovations in the services offered to final consumers may require investments in both the services provided by the competitive and noncompetitive activities." ${ }^{32}$ The OECD did not attempt to quantify the effects of these countervailing forces on industry innovation, so it is not evident that ownership separation would result in greater innovation.

The OECD also advocated the separation of the ILEC into smaller vertically integrated carriers because it believed that doing so would promote interconnection by reducing the bargaining position of monopoly telephone providers, without jeopardizing economies of scope. ${ }^{33}$ The fallacy of such reasoning is that the goal of promoting interconnection could be accomplished through the far less restrictive means of open access regulation. In the United States, for example, interconnection prices, terms, and conditions are regulated by the state public utilities, and, thus, the OECD's concern with high interconnection rates is largely irrelevant. ${ }^{34}$

Finally, the OECD admitted that behavioral remedies, such as access regulation or restrictions on retail operations, could also curtail the vertically integrated firm's ability to discriminate against competitors. The OECD concluded, however, that such behavioral regulation can never be fully effective:

An integrated firm, in contrast to a separated firm, benefits from any action which delays the provision of, raises the price or lowers the quality of access. An integrated firm will therefore use whatever regulatory, legal, political or economic mechanisms are in its power to delay, restrict the quality or raise the price of access. Furthermore, the integrated firm has strong incentives to innovate in this area, constantly developing new techniques for delaying access. Although the regulator can address these techniques as they arise, it is likely to always be "catching up" with the incumbent firm. Regulation, despite its best efforts, is unlikely to be able to completely offset the advantage of the incumbent. ${ }^{35}$

\footnotetext{
32 Id. $9960,82$.

33 Id. 1190.

34 The OECD stated that few countries have pursued regional separation, but noted that the United States divided AT\&T into seven regional operating and one long-distance company, and that "the U.S. telecommunications regime is currently one of the most competitive in the world." Id. \152. In 1999, Japan similarly divided NTT into two regional operating companies and one long-distance company. Id. at 79, tbl.A-10. However, a holding company still owns these separate business units. 35 Id. $\uparrow 66$.
} 
The OECD failed to recognize that it is not the regulator's job to "completely offset the advantages of the incumbent." This statement suggests a competitor-welfare orientation. Such a focus takes no account of advantages enjoyed by the incumbent as a result of superior efficiency. The proper measure of any regulation is not the extent to which it purportedly makes the regulator's job easier, but rather the extent to which it can achieve its desired end-the enhancement of consumer welfare-by the least restrictive means.

In summary, although the OECD asserted that structural separation is the best way to promote competition, it did not provide convincing evidence that such separation would alter the incentives of the firm. For example, the wholesale provider might enter into exclusive arrangements with particular retailers to achieve efficiencies or to align incentives, or both. Furthermore, the OECD's criteria for judging the usefulness of structural separation are flawed, both in their focus on competitor welfare and in their emphasis on the ease of regulation to the exclusion of consumer welfare maximization.

\section{Structural Separation in Practice}

On the surface, mandatory structural separation would seem to involve the simple separation of the ILEC's wholesale local exchange functions from its retail local exchange functions. But the Pennsylvania PUC came to regard the promised simplicity of structural separation as illusory. The Commission subsequently retreated from its original imposition of structural separation on Bell Atlantic-Pennsylvania until all that remained was a code of conduct. ${ }^{36}$ The Florida PSC similarly concluded that structural separation was not necessary for effective competition, and that it would confound current regulatory efforts before they have been tested.

\section{The Pennsylvania PUC's Experience}

To understand better what the implementation of structural separation would entail, it is informative to examine the original proposals contemplated but rejected by the Pennsylvania PUC. The Pennsylvania

36 The Pennsylvania PUC rejected AT\&T's proposals to retain the separate wholesale affiliate's ILEC status (subject to existing rate and quality-of-service regulation by the PUC), while the separate retail affiliate's noncompetitive services would remain subject to price-cap regulation. Structural Separation of Bell Atlantic-Pennsylvania, Inc., Retail and Wholesale Operations, Dkt. No. M-00001353, at 24, Pa. Pub. Util. Comm'n, Mar. 22, 2001 (opinion and order) [hereinafter Pennsylvania Opinion and Order]. 
PUC also revealed, when it imposed a form of structural separation on Bell Atlantic-Pennsylvania in 2001, that the actual implementation of structural separation was complex and involved conduct remedies.

In September 1999, the PUC issued a "Global Order" instructing Verizon to structurally separate its wholesale operations from its retail operations. The PUC asserted in the Global Order that structural separation was not only the most efficient tool to ensure local service competition, but also necessary to accomplish that goal.

In October 2000, Pennsylvania's Commonwealth Court upheld all aspects of the PUC's Global Order, which had paved the way for the PUC's Structural Separation Order of April 2000. ${ }^{37}$ The order mandated the full separation of Verizon's wholesale and retail branches, absent proof by Verizon that full structural separation would be "unreasonably costly, unduly burdensome, or confiscatory." ${ }^{38}$ In January 2001, an administrative law judge found that Verizon's filings failed to make the necessary showing. ${ }^{39}$ He rejected Verizon's alternative proposal to split off an advanced data services affiliate and directed Verizon to begin a one-year transition to full structural separation. ${ }^{40}$

In a reversal of its previous defense of the superiority of structural separation over conduct remedies (and its notion that structural separation could largely supplant conduct remedies), the Pennsylvania PUC acknowledged in its March 2001 Opinion and Order that either full or functional separation would require substantial implementation costs and complementary behavioral remedies, and that neither would reduce regulatory oversight:

[A]nything less than full structural separation would require continuing regulatory oversight, even though part of our goal in deregulating the industry is to reduce oversight. However, . . . even with the implementation of structural separation of Verizon's wholesale and retail arms, no less regulatory oversight than that currently prevailing will be required to ensure compliance. ${ }^{41}$

37 Structural Separation of Verizon Pennsylvania, Inc., Retail and Wholesale Operations, Dkt. No. M-00001353, at 10, Pa. Pub. Util. Comm'n, Jan. 2001 (recommended decision).

$38 \quad$ Id. at 5,10 .

39 Id. at 14.

40 Id.

41 Pennsylvania Opinion and Order, supra note 36 , at 47 
One commissioner subsequently said that structural separation "didn't look like as much of a silver bullet when we looked at the details of it." ${ }^{, 42}$ To address these difficulties inherent in structural separation, the PUC devised a novel two-pronged form of separation, which it called "functional/structural separation., ${ }^{, 43}$ The first prong mandated that the ILEC undertake "functional separation" of its wholesale and retail unitsthat is, the ILEC would have to separate its wholesale and retail divisions in a way that "provides for non-discriminatory access to its wholesale division by all CLECs." ${ }^{44}$ Activities that the Pennsylvania PUC functionally separated from Verizon's wholesale operations included personnel, accounting, record keeping, and business practices. The second prong directed the ILEC to create an advanced-services affiliate, separate from the retail division of its business. ${ }^{45}$

To identify specific behavioral constraints, the Pennsylvania PUC reopened a separate proceeding regarding the "code of conduct" governing Verizon. ${ }^{46}$ Moreover, the Commission imposed ten additional behavioral requirements on Verizon: ${ }^{47}$

- compliance with rules guaranteeing the interconnection of advanced services with CLECs;

- compliance with rules guaranteeing a CLEC's access to digital subscriber line access multiplexers ("DSLAMs") in remote terminals consistent with an industry standard (to be determined in a technical workshop);

- implementation of a technical trial of electronic loop provisioning;

- creation of a collaborative body to address the design of next generation digital line carrier ("NGDLC") and equal access to digital subscriber line ("DSL") over fiber;

- implementation of rules guaranteeing monthly meetings for CLECs, which will be arbitrated by a PUC Commissioner;

- creation of a collaborative body to address the issue of line splitting;

- withdrawal by Verizon of all state and federal court challenges to the Global Order mandating structural separation;

42 Chris Sewell, Still Together, TELEPHONY, Apr. 2, 2001 (quoting PUC Commissioner Terrance J. Fitzpatrick).

43 Pennsylvania Opinion and Order, supra note 36 , at 30

$44 \quad$ Id. at 59.

45 Id.

$46 \quad$ Id. at 60.

47 Id. at $49-57$ 
- increased penalties to be paid by Verizon if it does not comply with certain metrics-for example, liquidated damages were increased an additional $\$ 1,000$ per metric violated;

- decreased rates for two-wire loops in the most rural areas of the state; and

- retention of responsibility by Verizon for network modernization.

The Pennsylvania PUC's decision to impose a full complement of behavioral remedies in conjunction with functional separation demonstrates that it was not confident that such separation would quickly diminish the need for regulation.

The Pennsylvania PUC originally retreated from mandatory structural separation because it came to recognize that structural separation involved much more regulatory oversight than the actual or functional bifurcation of an ILEC's wholesale and retail assets. In effect, the Pennsylvania PUC repudiated its original determination in September 1999 that structural separation was the "most efficient tool to ensure local telephone competition where a large incumbent monopoly controls the market., ${ }^{, 48}$ Ultimately, the Pennsylvania PUC decided in November 2001 to reject its directive for full functional separation and to rely instead on its code of conduct to promote competition. In December 2001, Commissioner Terrance Fitzpatrick called functional separation an "intrusive remedy designed to fix a problem that has not been shown to exist,"49 citing the FCC's approval of Verizon's Section 271 application in Pennsylvania. ${ }^{50}$

\section{The Florida PSC's Experience}

In March 2001, AT\&T Communications, TCG South Florida, and MediaOne Florida Telecommunications petitioned the Florida Public Service Commission ("PSC") to order the structural separation of BellSouth. The petitioners alleged that BellSouth had engaged in anticompetitive actions, and that full structural separation was necessary to

\footnotetext{
48 Pennsylvania Global Order, supra note 9, at 222.

49 Glenn Bischoff, Pennsylvania Loss Reflects AT\&T's Regulatory Struggles, TELEPHONY, Dec. 10, 2001.

so Id.; see also Motion of Commissioner Terrance J. Fitzpatrick, Implementation of the Telecommunications Act of 1996, Imputation Requirements for the Delivery of IntraLATA Services by Local Exchange Carriers, Dkt. No. M-00960799, Pa. Pub. Util. Comm'n ("In light of the conclusion of this Commission and the FCC that Verizon's local market is open-including a finding that Verizon is providing wholesale services in a non-discriminatory manner[,]. . . it is not necessary to require Verizon to separate all of its employees and facilities into separate wholesale and retail divisions. I note that neither the United States Congress, nor the FCC, nor any other state has deemed such a reorganization of an ILEC necessary in order to protect competition.").
} 
promote competition in local markets. ${ }^{51}$ The PSC responded by conducting a series of workshops on structural separation and local exchange competition. $^{52}$

After the final workshop, in November 2001, the PSC granted BellSouth's motion to dismiss the CLECs' petitions on the grounds that the PSC lacked any authority to impose structural separation, and, therefore, it could not grant the relief requested by the petitioners. ${ }^{53}$ The PSC criticized the CLECs' petition as "a solution in search of a problem" and noted that the CLECs had "request[ed] relief so draconian that of the states that have examined the issue, all have rejected it." 54 Most importantly, the PSC rejected the CLECs' contention that structural separation was necessary for local competition:

To find that structural separation is necessary to promote competition, as the Petitioners urge, implies at best, that we question our confidence that the other dockets will promote competition; and at worst, that our earlier efforts have been in vain. Similarly, this most recent Petition either is cumulative, or will interfere with, our earlier efforts, many of which are ongoing. ${ }^{55}$

The Florida PSC recognized that a hasty implementation of structural separation would have the practical effect of superseding existing openaccess remedies before the PSC could determine their efficacy:

Each additional regulation imposed on BellSouth creates costs and inefficiencies; may interfere with other regulations previously imposed; and brings uncertainty to an industry in which stability is necessary to foster competition. Not only is it premature to judge the efficacy of our earlier efforts, but it is also premature to determine that another solution is necessary. ${ }^{56}$

Finally, in the aftermath of the September 11, 2001 terrorist attacks, the Florida PSC found that structurally separating BellSouth could hamper its

51 Petition of AT\&T Communications, supra note 9.

52 Order Granting BellSouth's Motion to Dismiss AT\&T's and FCCA's Petitions for Structural Separation, Dkt. No. 010345-TP, at 2, Fla. Pub. Serv. Comm'n, Nov. 6, 2001, available at http://www.psc.state.fl.us/dockets/documents/01/13992-01.html.

$53 \quad$ Id. at 6.

54 Id. at 7,8

$55 \quad$ Id. at 8.

56 Id. at 8. 
ability to react to national emergencies, describing this hindrance as "a risk to our economy and consumers that we are not willing to take." 57

In short, the Florida PSC concluded that it lacked jurisdiction to order structural separation. It rejected the contention that structural separation was necessary for local competition. To the contrary, the Florida PSC concluded that structural separation would confound existing regulatory efforts aimed at promoting such competition.

\section{The Purported Merits of Mandatory Structural Separation}

There are principally two purported benefits to mandatory structural separation. First, according to its proponents, structural separation would guarantee nondiscriminatory access to the ILECs' networks. For example, CompTel has argued that the incentives established under the Telecommunications Act of 1996 are insufficient to induce ILECs to offer nondiscriminatory access to their networks. By changing course, CompTel reasoned, state PUCs "can create an environment where an ILEC's own commercial success depends upon its ability to offer efficient access to the existing network." 58 In its formal petition for mandatory structural separation of Verizon in New Jersey, AT\&T argued that such regulatory intervention would accomplish, among other things, nondiscriminatory access by competitors to the components of Verizon's network ${ }^{59}$ - that is, unaffiliated and affiliated retailers of local telecommunications services would be treated equally in the provision of UNEs.

Second, structural separation purportedly would lower wholesale discount rates. To justify mandatory structural separation of the ILECs in the local market, Mr. Armstrong argued that the divestiture of AT\&T's long-distance operations from the local-exchange operations of the former Bell System produced greater wholesale discounts (for long-distance resellers) that are significantly lower than the wholesale discounts charged by the ILECs for local services. He claimed that wholesale discounts for long-distance service are five times larger than wholesale discounts for local service (55\% in long-distance service versus $10 \%$ in local service). ${ }^{60}$ In Part II, we examine critically AT\&T's diagnosis of the CLECs' problem and its proposed solution.

\footnotetext{
57 Id. at 10.

58 COMPTEL STUDY, supra note 16 , at 6.

59 Press Release, AT\&T, AT\&T Files Formal Petition for "Structural Separation" of Verizon-New Jersey (Feb. 28, 2001) (on file with author).

60 Armstrong Warns AT\&T May Pull Out of Local Phone Markets, COMM. DAILY, Feb. 8, 2001 [hereinafter Armstrong Warns].
} 


\section{E. Japan's Cautious Evaluation of Structural Separation}

In Japan, the Ministry of Public Management, Home Affairs, Posts and Telecommunications ("MPHPT") closely monitors developments in U.S. telecommunications policy. For example, the Japanese approach to ordering the reorganization of Nippon Telegraph and Telephone into separate long-distance and regional local exchange companies resembled the AT\&T divestiture in the United States. ${ }^{61}$ Given Japan's general receptivity to American approaches to telecommunications regulation, it is noteworthy that the MPHPT has taken a cautious approach to structural separation after carefully studying the debate on the issue in the United States.

In February 2002, MPHPT received, from an expert group called the Telecommunications Council, the second in a series of reports containing recommendations for Japanese telecommunications policy. ${ }^{62}$ Upon receiving the report, the MPHPT said that it would "take appropriate measures on the report." ${ }^{\prime 3}$ In what it called Stage One of its procompetitive policies, the Council advocated further openness of the networks of NTT East and NTT West, in part through reliance on "rigorous firewalls to provide functional separation." ${ }^{164}$ The Council also outlined a more invasive Stage Two:

61 See, e.g., Robert W. Crandall, Telecommunications Liberalization: The U.S. Model, in DEREGULATION AND INTERDEPENDENCE IN THE ASIA-PACIFIC REGION 415 (Takatoshi Ito \& Anne O. Krueger eds., 2000). In June 1997, the Japanese Diet authorized a plan of reorganization for NTT that the predecessor agency of the MPHPT, the Ministry of Post and Telecommunications, had proposed and NTT had accepted in principle. See NIPPON TELEGRAPH AND TELEPHONE CORPORATION, ANNUAL REPORT 2001, at 13 (for the year ended Mar. 31, 2001). Once the reorganization took effect on July 1, 1999, NTT became a holding company with several wholly owned subsidiaries, including NTT East, NTT West, NTT Communications, and NTT DoCoMo (a wireless company). Id. NTT East and NTT West are both regional fixed-line operators analogous to a regional Bell operating company in the United States.

The MPHPT receives more than subtle encouragement to follow American regulatory practices. The U.S. Trade Representative cajoles Japan, upon implicit threats of trade sanctions, to emulate U.S. regulatory policies concerning local telecommunications. See Jeffrey H. Rohlfs \& J. Gregory Sidak, Exporting Telecommunications Regulation: The U.S.-Japan Negotiations on Interconnection Pricing, 43 HARV. INT'L L.J. (forthcoming 2002).

62 TELECOMMUNICATIONS COUNCIL, SECOND REPORT ON DESIRABLE PRO-COMPETITIVE POLICIES IN THE TELECOMMUNICATIONS BUSINESS FIELd FOR PROMOTING THE IT REVOLUTION (INQUIRY No. 29 of 2000) (Feb. 13, 2002) (prepared for MPHPT), printed in 12 MPHPT COMMUNICATIONS NEWS, no. 24, Mar. 18, 2002, at 1 (English summary posted at http:/www.soumu.go.jp/joho_tsusin/eng/index.html) [hereinafter SECOND REPORT]; see also Panel Threatens NTT with Splitup, JAPAN TIMES ONLINE, Dec. 13, 2001, at http://www.japantimes.co.jp/cgibin/getarticle.pl5?nb20011213a7.htm (last visited Apr. 5, 2002).

63 SECOND REPORT, supra note 62, at 1.

64 Id. ch. 1 I 8(1), at 2 ("Proceed with opening up network access such as resale of public networks and opening up of OSS [operations support systems], together with rigorous firewalls to provide functional separation. Furthermore, there are expectations for new entry from other sectors and increased new market entry when the business category classification is revised."). 
Stage 1 considers a variety of non-structural pro-competitive policies. Of those, if the resale of public networks and access to fiber-optic networks, which the report gives special emphasis to, have not been implemented despite proper requests from competitors, and sufficient competition cannot be seen in regional telecommunications markets after two years, fundamental review of NTT's management system will be quickly required. In such a case, various options should be considered such as full capital separation and separation of wholesale and retail operations. ${ }^{65}$

In other words, the Council concluded that it would be inappropriate for the MPHPT even to consider ordering structural separation of wholesale and retail operations of NTT East and NTT West unless two years' experience proved functional separation to be inadequate to protect competition.

If structural separation were deemed necessary, MPHPT would then need to specify its form. Having studied other countries, the Council identified two different approaches to structural separation: "one in which existing regional carriers move toward structural separation on their own to request deregulation, and one in which the regulatory authorities require the regional carriers to undergo structural separation." variant is exemplified by the original structural separation plan of the Pennsylvania PUC, described earlier. The first variant is exemplified by voluntary and unsolicited plans for structural separation, which we discuss later in Part II. ${ }^{67}$ Although the Council noted that, "[i]n both of these cases, the orientation of the eventual trend is still unclear,"68 it nonetheless said that mandatory structural separation "is worth examining as one of the options in drastically reviewing the management format of NTT East and NTT West.",69

The Council, however, recognized several disadvantages of structural separation. Such regulatory intervention would be protracted, costly, and controversial-as well as uncertain in its efficacy because, the Council observed, "there are no actual cases in other countries, and it is hard to generate confidence that a smooth implementation is possible.,70 Moreover, "the monopolistic status of bottleneck facilities will not change

\footnotetext{
65 Id. ch. 1 \8(2), at 2.

66 Id. ch. 1 I 7(1), at 2.

67 See infra Subsection II.C.4.d.

68 SECOND REPORT, supra note 62, at ch. 1 ๆ 7(1), at 2.

69 Excerpt from English Translation of Entire Second Report, $\uparrow 7(3)(b)(1)(J a n .30,2002)$ (provided by NTT West; copy on file with authors). The MPHPT website contains only an English summary of the report, not an English translation of the entire report.

$70 \quad$ Id. $\uparrow 7(3)(\mathrm{c})(1)$.
} 
before or after structural separation." ${ }^{, 71}$ Consequently, the Council noted, the goal of a competitive local telecommunications market "would better be addressed" through policies on interconnection pricing and investment. $^{72}$

\section{A Critique of AT\&T's Hypothesis and Its Proposed Remedy}

AT\&T argues that CLECs have failed because the ILECs have acted anticompetitively. AT\&T's proposed remedy is mandatory structural separation of the ILECs. We consider now why AT\&T's hypothesis is unpersuasive and its remedy a socially costly non sequitur.

\section{A. The Inability of Allegedly Anticompetitive Practices to Explain Market and Regulatory Phenomena}

The hypothesis of the proponents of structural separation is inconsistent with many facts concerning regulation and actual competitive entry.

1. The Steady Increase in CLECs' Market Share

Despite the much-publicized bankruptcy of individual firms, the CLECs collectively have fared well. According to FCC data released in February 2002, CLEC market share grew by $109 \%$ during the eighteen months between the end of 1999 and the end of June $2001 .{ }^{73}$ CLECs reported 17.3 million (or 9.0\%) of the approximately 192 million nationwide local switched-access telephone lines in service to end-users on June 30,2001 , compared with 8.2 million (or $4.3 \%$ of nationwide lines) of 189.5 million lines at the end of $1999 .{ }^{74}$ For the medium and large business market, CLEC lines numbered 9.5 million (or $19.1 \%$ of nationwide business lines). ${ }^{75}$ For the residential and small businesses market, CLECs supplied 7.8 million lines (or $5.5 \%$ of nationwide residential and small business lines). ${ }^{76}$ Because of the geographic clustering of business customers, there are large economies of density in serving the business

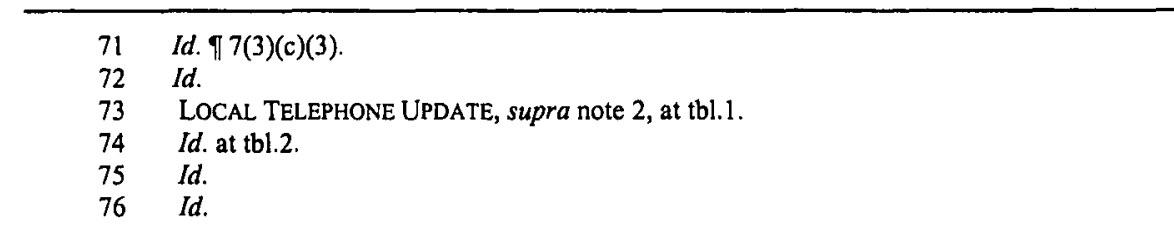


market. Hence, it is no surprise that CLECs have focused their entry initiatives on the business markets. Figure 1 shows the CLEC market share of all nationwide end-user telephone lines as of December 2000.

\section{Figure 1. CLEC Share of Nationwide End-User Telephone Lines}

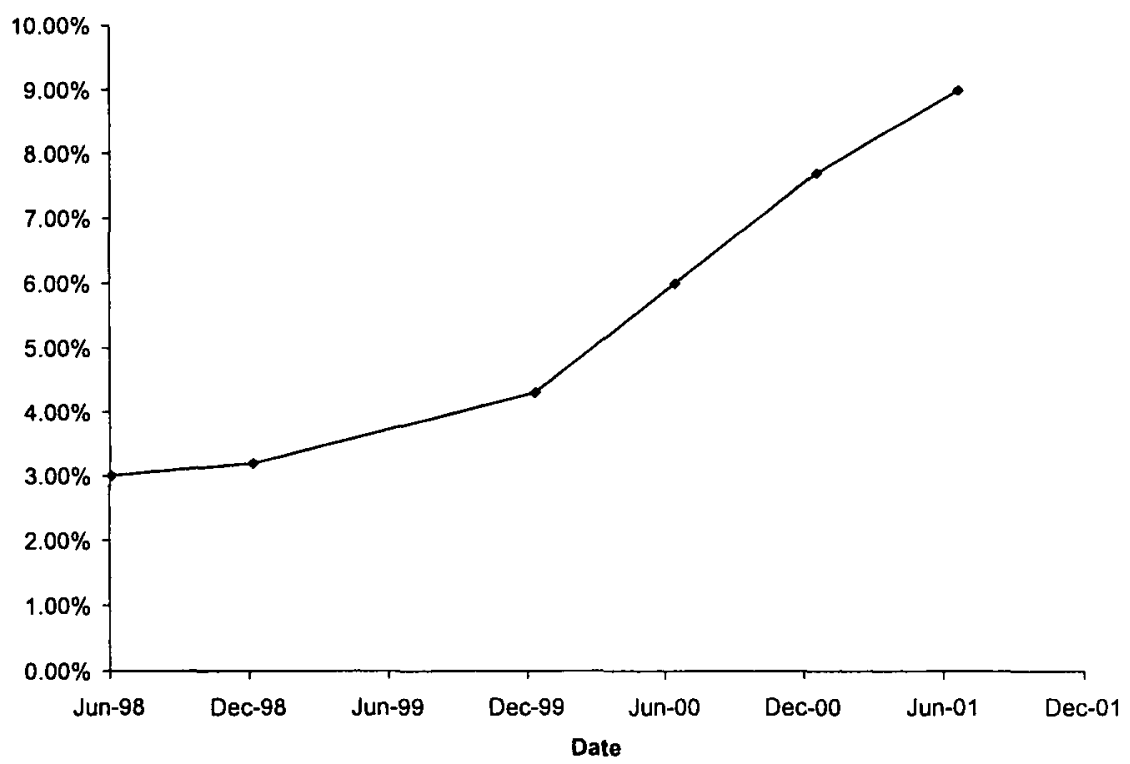

Sources: Local Competition, Industry Analysis Division, Common Carrier Bureau, at 6, Dec. 1998; FCC News Release, Federal Communications Commission Releases Latest Data on Local Telephone Competition, at 2 (Aug. 31, 1999), at 2; FCC News Release, Federal Communications Commission Releases Latest Data on Local Telephone Competition, at tbl.1 (Feb. 22, 2002).

As Figure 1 demonstrates, CLECs are gaining market share at a brisk pace. In some individual markets, CLEC market shares are considerably higher than Figure 1 suggests. In a city-by-city analysis of CLEC entry in New York state, for example, the New York Public Service Commission found that, as of the end of 2000, CLEC market shares exceeded 15\% in Albany, Syracuse, and Buffalo and exceeded $20 \%$ in New York City and Rochester. ${ }^{77}$ Figure 2 presents these data. As Figure 2 shows, the CLECs' share in New York City has increased from $6 \%$ to $23 \%$ over a period of three years. 
Figure 2. CLEC Market Shares in New York State, 1998-2000

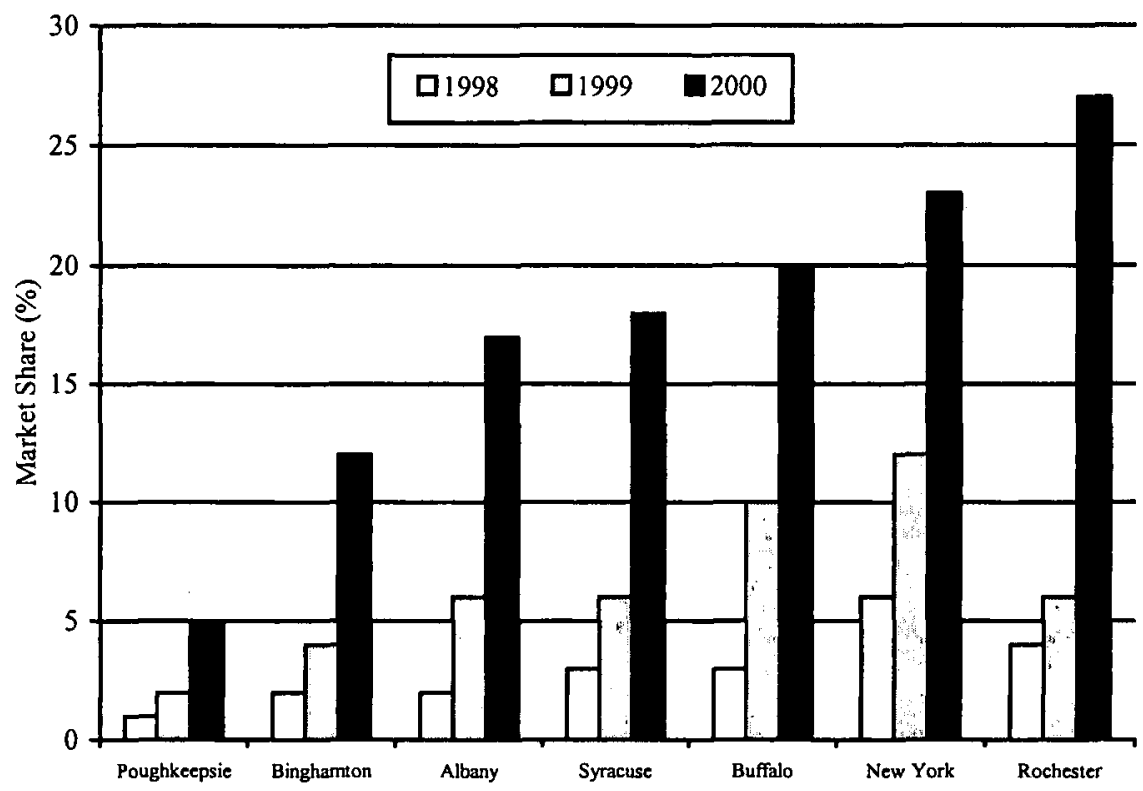

Source: New YoRK State PUblic SeRVICE COMMISSION, supra note 3, at 5.

It would be a mistake, however, to judge the growth of competition in local telephony since passage of the Telecommunications Act of 1996 solely by measuring CLEC market share in local services over time. The welfare of local service consumers (as opposed to local service suppliers) will increase as prices more accurately reflect costs or as the quality of local exchange service increases. Hence, regulators and legislators should focus more on the prices and quality of the service offerings rather than fixate on CLEC market share. For example, simply because AT\&T can provide local telephony services over its unregulated cable platform, there is no guarantee that those consumers who wish to switch from ILEC service will be better off. It is also doubtful whether a CLEC providing service over an ILEC's network can offer end users a service at a lower price or a better service at the same price. Hence, high CLEC market share might not correlate with increased consumer welfare in the context of regulated retail rates.

What would be the proper benchmark to determine, as Goldilocks might, whether that rate of decline in the ILECs' market share is too fast, too slow, or just right? By June of 2001, the ILECs supplied over $90 \%$ of 
the local (non-cable) landline switched-access lines. ${ }^{78}$ But, as of June 2001, Verizon had lost $13 \%$ of end-user switched-access lines in Pennsylvania to CLECs, up from $8 \%$ a year earlier. ${ }^{79}$ The attainment of competitive markets for local telephony should not become a process of monitoring the ILECs' eroding market share, along the lines of the FCC's obsession in the 1980s with defining the competitiveness of long-distance markets in terms of the erosion of AT\&T's dominant share. ${ }^{80}$ Ultimately, legislators, regulators, and courts should judge the competitiveness of the local services market (and the success of the Telecommunications Act of 1996) from the perspective of the consumer-not that of a particular competitor. ${ }^{81}$ That criterion, after all, is precisely what the preamble of the 1996 legislation establishes, as we noted in the first sentence of this Article. $^{82}$

In the Sections that follow, we describe the growing competition for local services in both the large business market and the residential and small business markets.

\section{a. The Large Business Market}

The CLECs have rapidly deployed fiber lines to offer local services in business districts. From 1997 to the end of 2000, the number of route miles of fiber that CLECs had deployed grew from 78,506 to $218,445 .{ }^{83}$ Over the same period, the number of installed voice switches owned by CLECs grew from 334 to 991 , and the number of installed data switches grew even more rapidly, from 331 to $2,071 .^{84}$ Furthermore, several of the nation's largest operators of long-haul fiber networks have constructed local fiber networks and now lease dark fiber on those networks to CLECs. ${ }^{85}$

78 LOCAL TELEPHONE UPDATE, supra note 2.

79 Id. at tbl.7.

80 See Simran K. Kahal, David L. Kaserman \& John W. Mayo, Is the "Dominant Firm" Dominant? An Empirical Analysis of AT\& T's Market Power, 39 J.L. \& ECON. 499 (1996); John Haring \& Kathy Levitz, What Makes the Dominant Firm Dominant? (FCC, Office of Plans and Policy, OPP Working Paper No. 25, Apr. 1989).

81 See Jerry A. Hausman \& J. Gregory Sidak, A Consumer-Welfare Approach to the Mandatory Unbundling of Telecommunications Networks, 109 YALE L.J. 417 (1999).

82 See supra text accompanying note 1.

83 ASSOCIATION FOR LOCAL TELECOMMUNICATIONS SERVICES, THE STATE OF LOCAL COMPETITION 2000, at 25, available at http://www.alts.org/Filings/022001AnnualReport.pdf [hereinafter ALTS REPORT].

84 Id. at 24.

85 United States Telecom Association, Competition for SPECIAl ACCESS SERVices, HIGH-CAPACITY LOOPS, AND INTEROFFICE TRANSPORT, at 3 (Apr. 5, 2001) (prepared for BellSouth, SBC, Qwest, and Verizon) [hereinafter USTA STUDY]. 
Individual CLECs have deployed fiber networks at a rapid pace. For example, in November 2000, Sprint announced that it was deploying local fiber rings in twenty major U.S. markets. ${ }^{86}$ Williams expects to spend $\$ 421$ million between 2000 and 2003 to link its proposed 33,000-mile fiberoptic backbone network directly to business customers in the nation's largest cities. ${ }^{87}$ Qwest is building local fiber rings in twenty-five major metropolitan markets to give customers direct, high-speed connections to Qwest's global broadband Internet network. ${ }^{88}$

The availability of competitive alternatives to the high-capacity loops and interoffice transport that ILECs provide to businesses is widespread and has continued to grow rapidly. From 1999 to 2001, there has been a dramatic increase in local fiber supplied by "carrier-agnostic" wholesale suppliers. ${ }^{89}$ For a growing number of CLECs, the fiber provided by these wholesale suppliers satisfies a large part of their demand for last-mile local connectivity and interoffice transport.

\section{b. The Residential and Small Business Markets}

In contrast to the massive investment by CLECs in business areas, CLEC investment in residential areas has been slower because of two regulatory distortions. Additional investment could be encouraged in those areas by more efficient pricing of UNEs, wholesale rates, and retail rates for residential customers. Rules requiring mandatory unbundling at prices based on total element long-run incremental cost ("TELRIC") distort CLECs' incentives to invest in their own facilities in several ways. First, the pricing policies of the FCC on UNEs have encouraged CLECs' reliance on ILEC facilities. Pricing access too low not only distorts the decision of incumbents, ${ }^{90}$ but also undermines the incentive to invest by

86 Press Release, Sprint FON Group, Sprint Announces Financial Targets and Growth Strategies (Nov. 3, 2000) (on file with author).

87 Corey Grice, Williams to Expand High-Speed Network into 50 Cities, NEws.COM, Feb. 10, 2000, http://news.cnet.com/news/0-1004-200-1546995.html?tag=st.

88 Press Release, Qwest Communications, Qwest Communications Launches High-Speed Broadband Access Services to Businesses in Four Texas Markets (Oct. 25, 2000) (on file with author).

89 USTA STUDY, supra note 85 , at 2.

90 Unbundling at TELRIC-based prices truncates the high-end of the distribution of returns on investment for ILECs, which reduces their incentive to invest in new facilities. See Hausman \& Sidak, supra note 81 . For empirical validation of this relationship, see Eisner \& Lehman, infra note 246; see also Alfred E. KAHN, LetTING Go: DeREgulating THE PROCESS OF DEREgUlation (1998) [hereinafter KAHN, LETTING Go]; Thomas M. Jorde, J. Gregory Sidak \& David J. Teece, Innovation, Investment, and Unbundling, 17 YALE J. ON REG. 1 (2000); Jerry A. Hausman, The Effect of Sunk Cost in Telecommunications Regulation, in THE NEW INVESTMENT THEORY OF REAL OPTIONS AND ITS IMPLICATION FOR TELECOMMUNICATIONS ECONOMICS (James Alleman \& Eli Noam eds., 1999); J. Gregory Sidak \& Daniel F. Spulber, Givings, Takings, and the Fallacy of Forward-Looking Costs, 72 N.Y.U. L. REv. 1068 (1997); J. Gregory Sidak \& Daniel F. Spulber, The Tragedy of the 
CLECs. Because a CLEC cannot redeploy many of the elements of a telecommunications network if they prove to be uneconomical, it pays for the CLEC to "wait and see" how well other investments in the telecommunications industry have performed before committing itself to investing its own capital. ${ }^{91}$

Second, when considered alongside the artificially depressed prices of residential local service in many states, the cost-based pricing of network elements-no matter how low-would not encourage entry by CLECs. To provide telecommunications services to all residents, the FCC and the state PUCs have designed a cross-subsidy scheme that restricts the price of residential service below costs. ${ }^{92}$ In particular, the returns from providing local service to business customers are used to support residential rates. ${ }^{93}$ It is no accident that CLECs first target business customers rather than residential customers. No unregulated profit-maximizing firm would voluntary absorb a share of the universal service fund required to serve residential customers at below-cost rates.

\section{Regulatory Approval for RBOC Entry into Long-Distance Services}

There exists a separate "reality check" on the claim that the ILECs have engaged in anticompetitive behavior toward CLECs and that such behavior necessitates mandatory structural separation. The entry of the regional Bell operating companies into the interLATA long-distance markets is subject to intense regulatory scrutiny under Section 271 of the Communications Act. ${ }^{94}$ The fact that the RBOCs have received Section 271 approvals in eleven states as of April $2002^{95}$ implies that the

Telecommons: Government Pricing of Unbundled Network Elements Under the Telecommunications Act of 1996, 97 Colum. L. REv. 1081 (1997) [hereinafter Sidak \& Spulber, The Tragedy of the Telecommons].

91 For an application of real options analysis to telecommunications investment, see Hausman \& Sidak, supra note 81.

92 See, e.g., ROBERT W. CRANDALl \& LEONARD WAVERMAN, WhO PAYS FOR UNIVERSAL SERVICE?: WHEN TELEPHONE SUBSIDIES BECOME TRANSPARENT (2000).

93 See id:; Karen Palmer, A Test for Cross Subsidies in Local Telephone Rates: Do Business Customers Subsidize Residential Customers?, 23 RAND J. ECON. 415 (1992).

9447 U.S.C. $\$ 271$ (2000). For an economic assessment of the rigors of Section 271 entry process, see Paul W. MacAvoy, Testing Competitiveness of Markets for Long Distance Telephone Services: Competition Finally?, 13 REV. INDUS. ORG. 295 (1998).

95 As of April 20, 2002, the BOCs had received Section 271 authorizations in eleven states on the following dates: Arkansas (Nov. 16, 2001), Connecticut (July 20, 2001), Kansas (Jan. 22, 2001), Massachusetts (Apr. 16, 2001), Missouri (Nov. 16, 2001), New York (Dec. 22, 1999), Oklahoma (Jan. 22, 2001), Pennsylvania (Sept. 19, 2001), Rhode Island (Feb. 24, 2002), Texas (June 30, 2000), and 
respective state PUCs and the FCC and the U.S. Department of Justice had determined that entry conditions in those local markets were sufficiently open to allow local competition. That is, eleven state PUCs and the FCC and the Department of Justice had determined by April 2002 that mandatory structural separation of the wholesale and retail divisions of the local Bell operating company was not necessary to ensure a competitive local services market. It is hardly credible that entry conditions in those eleven states are so different from the conditions that prevail in New Jersey or Virginia that a separate economic test must be applied in the latter set of states. More likely, the proponents of mandatory structural separation recognize that, as long as the state PUCs, the FCC, and the Department of Justice judge the RBOCs under the entry conditions articulated in Section 271 and amplified in the FCC's First Report and Order on local interconnection, ${ }^{96}$ the RBOCs will gain entry into the longdistance markets of a significant number of other states and thereby erode long-distance carriers' margins by late 2002 .

\section{Other Factors that Suggest Greater Competition}

Although residential and small business markets have attracted less facilities-based entry by CLECs than the large business market has, it is nonetheless true that cable television and wireless provide an access substitute for many residential wireline customers. Such substitution is widespread enough to have given rise to the phrase "landline displacement," which we now consider.

\section{a. Substitution from Cable Television}

Cable telephony was introduced as recently as 1999 and although AT\&T struggled initially, the number of cable telephony subscribers began to accelerate rapidly near the middle of 2000 . According to the FCC's Eighth Annual Report on Competition in Video Markets, as of January 2001, only circuit-switched cable telephony was commercially deployed, but trials had begun for cable-delivered (packet-switched) Internet-

\footnotetext{
Vermont (Apr. 17, 2002). See FCC, RBOC Applications to Provide In-region, InterLATA Services Under $\$ 271$, at http://www.fcc.gov/Bureaus/Common_Carrier/in-region_applications.

96 In re Implementation of the Local Competition Provisions in the Telecommunications Act of 1996, Interconnection between Local Exchange Carriers and Commercial Mobile Radio Service Providers, 11 F.C.C.R. 15,499 (1996) (First Report and Order), rev'd in part and aff'd in part sub nom. Iowa Utils. Bd. v. FCC, 120 F.3d 753 (8th Cir. 1997), rev'd in part and aff'd in part sub nom. AT\&T Corp. v. Iowa Utils. Bd., 525 U.S. 366 (1999) [hereinafter Local Competition First Report and Order].
} 
protocol ("IP") telephony. ${ }^{97}$ Cox and AT\&T continue to deploy circuitswitched cable telephony. ${ }^{98}$ Other cable companies, such as Cablevision and Comcast, were offering cable telephony on a limited basis, waiting instead for IP technology to become widely available before accelerating their rollout of telephone services to customers. ${ }^{99}$ Over 1.2 million customers received local telephone service through their cable system as of the end of $2000 .{ }^{100}$

Because cable firms reach over $80 \%$ of all U.S. households and the majority of those connections will be two-way enabled by the end of 2002, no amount of anticompetitive behavior by ILECs could prevent cable firms-such as AT\&T and AOL Time Warner-from capturing a large share of the local exchange market. Stated differently, the potential market share of local exchange service for cable telephony is only limited by the cable firms' collective ingenuity.

According to Mr. Armstrong of AT\&T, FCC regulations that limit the number of homes that a single cable multiple system operator ("MSO") may reach have prevented vigorous competition for the supply of local telephony to residential customers. Because of such limitations, $\mathrm{Mr}$. Armstrong argues, "the only chance for competitors like AT\&T to offer broad-based competition in the local market is to lease pieces of the Bells' facilities." ${ }^{101}$ On March 2, 2001, however, the U.S. Court of Appeals for the District of Columbia Circuit struck down, as unconstitutional, the FCC's regulations limiting the growth of the nation's largest cable MSOs and preventing them from presenting more of their own programs. ${ }^{102}$ Therefore, according to Mr. Armstrong's own logic, the D.C. Circuit's decision has increased AT\&T's ability to serve local customers outside AT\&T's current cable regions without having to lease network elements from the ILEC. Hence, since March 2001, unbundled access to the ILEC's network elements at regulated prices no longer constitutes the "only chance" for cable MSOs in general (and AT\&T in particular) to compete in the local services market.

97 Annual Assessment of the Status of Competition in the Market for the Delivery of Video Programming, Eighth Annual Report, 17 F.C.C.R. If 50 (2002) [hereinafter Eighth Report on Video Competition].

98 AT\&T expects to begin to transition to an integrated IP packet data architecture by the end of 2003. AT\&T CORP., SEC FORM 10-K405 (Apr. 4, 2001); MERRILL LYNCH, STOCKS REMAINED UNDER PRESSURE IN 2Q00, DESPITE SOLID FUNDAMENTALS 23 (2000).

99 Id.

100 Eighth Report on Video Competition, supra note 97, $9 \uparrow 155-58$.

101 Armstrong Warns, supra note 60 (emphasis added).

102 Time Wamer Entm't Co. v. FCC, 240 F.3d 1126 (D.C. Cir. 2001). A unit of AOL Time Warner, the nation's second-largest cable company after AT\&T, brought the case. The invalidated rule had prohibited a company from serving more than $30 \%$ of the cable and satellite television market and from providing more than $40 \%$ of its channels with programming from its affiliated companies. 
At a more fundamental level, Mr. Armstrong's complaint about the FCC's cable rules and the D.C. Circuit's decision striking them down are irrelevant. Reaching local customers through one's own facilities is becoming commonplace for the CLECs. Although CLECs may have originally deployed most of those facilities to target business customers, there is no reason that the CLECs cannot extend their networks to reach residential customers, first in denser areas and eventually elsewhere. Indeed, FCC data from June 2001 confirm that $45.1 \%$ of all CLEC lines serve residential and small business customers. ${ }^{103}$ The FCC's data refute Mr. Armstrong's assertion that the ILECs control the "only" route to the local customer.

Looking to the future, cable companies offer another method of substitution away from the ILEC as provider of network access. The combination of Internet protocol ("IP") telephony with instant messaging ("IM") technology has the potential to create an Internet-based alternative to the ILEC network. As soon as Microsoft and AOL Time-Warner agree on terms for exchanging IM traffic and then add voice-over-IP as a feature of IM, an instant private network will spring into being. It will initially encompass millions of users, and it will exist free of regulatory obligations or impediments. For consumers using cable modems for Internet access, this potential source of substitution away from the ILEC network illustrates how the competitive game has shifted from a narrowband marketplace to a broadband one in which voice telephony is a mere adjunct to a broader portfolio of service offerings. In that marketplace, it is erroneous to characterize competition as a relationship solely between ILECs and CLECs with respect to the delivery of narrowband applications. It is all the more perverse to consider the vertical disintegration of the ILECs as a useful public policy when the marketplace is evolving to a state in which the ILECs' principal rivals appear to be large media companies that are vertically integrated into both content origination and broadband delivery.

\section{b. Substitution from Wireless}

Competitive carriers continue to expand their use of wireless connections to reach local customers. For example, wireless carriers such as AT\&T and Sprint have used simplified rate plans to acquire former landline consumers. ${ }^{104}$ In particular, the fall in prices of regional and national wireless plans, combined with bundled-minute offerings, has

103 LOCAL TELEPHONE UPDATE, supra note 2, at tbl.2.

104 Karissa Todd, The Rate Race, WIRELESS REV., Feb. 1, 1999, at 92. 
made wireless attractive to many consumers. ${ }^{105}$ According to IDC, a telecommunications consultancy, those pricing trends are driving wireline minutes to wireless minutes, attracting new consumers, and increasing the wireless minute usage of current consumers. ${ }^{106}$ In 1999 , roughly $6.5 \%$ of the 2.1 trillion conversation minutes in the United States consisted of wireless calls. ${ }^{107}$ The Yankee Group, a technology research consultancy, has projected that, by 2005 , U.S. wireless use will grow to $41 \%$ of all conversation minutes. ${ }^{108}$ It attributed the phenomenon of landline displacement to "the arrival of all-inclusive wireless phone packages herald[ing] the arrival of cellular as a real alternative to landline telephony." 109 A recent study by Pulver.com, a telecommunications consultancy, found that, "in the 16 years since the Federal Communications Commission issued the initial cellular license, the wireless industry has erased the twentyfold wireline price advantage that existed in 1984," thus contributing to the landline displacement trend. ${ }^{110}$

The FCC has also documented the phenomenon of landline displacement. It noted in its Sixth Report on commercial mobile services that "[f]or some, wireless service is no longer a complement to wireline service but has become the preferred method of communication."111 In March 1999, Leap Wireless International began offering a flat-rate mobile plan designed to compete with wireline local telephone service. ${ }^{112}$ By the end of 2001, after less than three years of service, over 1.1 million

105 Id.

106 Id.

107 Judy Sarles, Wireless Users Hanging Up on Landline Phones, S.F. BUS. TIMES, Mar. 23, 2001, available at http:/ ssanfrancisco.bcentral.com/sanfrancisco/stories/2001/03/26/focus7.html.

108 Id.

109 According to the company, landline migration begins between 500 and 750 wireless minutes of use ("MOU") for users on an all-inclusive rate plan. Id. Displacement can occur at even lower usage levels, such as when wireless long-distance usage is high, or when users take advantage of the large home calling area for wireless service compared with wireline service. Id.; Steve Gold Cellular Poised to Displace Landlines-Yankee Report, NEWSBYTES, Jan. 4, 1999; see also J. Gregory Sidak, Hal J. Singer \& David Teece, A General Framework for Competitive Analysis in Wireless Telecommunications, 50 HASTINGS L.J. 1639 (1999).

110 Sarles, supra note 107.

111 In re Implementation of Section 6002(b) of the Omnibus Budget Reconciliation Act of 1993, Annual Report and Analysis of Competitive Market Conditions With Respect to Commercial Mobile Services, I6 F.C.C.R. 13,350, 13,381 (2001) (Sixth Report) thereinafter Sixth Report on Commercial Mobile Services].

112 In re Implementation of Section 6002(b) of the Omnibus Budget Reconciliation Act of 1993, Annual Report and Analysis of Competitive Market Conditions With Respect to Commercial Mobile Services, 14 F.C.C.R. 10,145, 10,157-58 (1999) (Fourth Report); see also Press Release, Leap Wireless International, Inc., Leap Wireless International Launches Cricket Service: Introducing 'Comfortable Wireless' for All Users, at http:/www.leapwireless.com/press/content/1999/31799.html (Mar. 17, 1999). 
customers had subscribed to Leap's service. ${ }^{113}$ Surveys of Leap customers reveal that $61 \%$ used the service as their primary telephone, ${ }^{114}$ and, according to Leap, roughly half of its subscribers view their wireless phones as replacements for their first or second phone lines. ${ }^{115}$ Other wireless carriers have subsequently offered similar services that compete for landline service. For example, in March 2000 Midwest Wireless launched in four Minnesota communities its "Realm" service, which gives customers one thousand minutes of local calling for a flat rate of $\$ 39.99$ per month. ${ }^{116}$

\section{B. The Inefficiency of Mandatory Structural Separation}

Even if one could document in a systematic way that discrimination by the ILECs is undermining local competition, it does not necessarily follow that mandatory structural separation would be an efficient remedy. The costs of mandatory structural separation are likely to exceed any purported benefits. A conduct remedy-for example, safeguards that would ensure the timeliness of provisioning network elements by the ILEC - could likely achieve the same goal in a less costly manner. Hence, the Pennsylvania PUC erred when it initially said in 1999 that structural separation was the "most efficient tool to ensure local telephone competition where a large incumbent monopoly controls the market."117 The definition of efficiency implies that there does not exist a lesser-cost alternative. ${ }^{118}$ But the costs associated with mandatory structural separation are surely significant. If a behavioral remedy (applied in conjunction with existing regulations on the ILEC's pricing of unbundled network elements ("UNEs") and wholesale rates) can achieve the same goal at lower costs, then mandatory structural separation cannot be the "most efficient" tool available to regulators, contrary to the initial view of the Pennsylvania PUC.

In March 2001, AT\&T released a study that claimed that the cost of mandatory structural separation would be small. ${ }^{119}$ According to the study,

113 Press Release, Leap Wireless International, Inc., Leap Reports Results for Fourth Quarter and Fiscal Year 2001, at http:/www.leapwireless.com/bcindex.html (Feb. 11, 2002).

114 See Press Release, Leap Wireless International, Inc., Leap Wireless International Reports Results For First Quarter of Fiscal 2000 (Jan. 5, 2000) (on file with author).

115 Sixth Report on Commercial Mobile Services, supra note 111, at 13,382.

116 Press Release, Minnesota Communities Receive First-Of-Its-Kind Wireless Phone Service (Mar. 27, 2000) (on file with author).

117 Pennsylvania Global Order, supra note 9, at 222.

118 See, e.g., William J. BAUMOL \& J. GREgORY SidAK, TOWARD COMPETITION IN LOCAL TELEPHONY 23-24 (1994) (explaining Pareto efficiency).

119 Press Release, AT\&T, Economist Finds Evidence Verizon is Grossly Exaggerating Cost of State-Required Verizon Split (Mar. 8, 2001) (on file with author). 
the out-of-pocket cost of mandating structural separation of Verizon's wholesale and retail units in Pennsylvania would not exceed \$41 million. ${ }^{120}$ From the outset, that analysis understated the true costs that Verizon and other ILECs would incur. ${ }^{121}$ The costs of mandatory structural separation would far exceed the ILEC's out-of-pocket costs. The total costs properly include the efficiency losses associated with vertical fragmentation of the ILECs, as well as the administrative costs of interpreting and enforcing a new regulatory regime.

A lengthy literature explains the efficiency reasons for vertical integration. Every other country has integrated telecommunications carriers for these efficiency reasons, which we now examine.

\section{The Coordination of Investment and Production Decisions}

Vertical integration enables a firm to coordinate investment and production decisions across its divisions. A comparison of the costs of contractual exchange with those of internal exchange often reveals vertical integration to be the least-cost method of achieving the desired level of coordination. ${ }^{122}$ The minimization of coordination costs is extremely important in a market subject to rapid technical change. Oliver Williamson has noted that vertical integration will produce efficiency gains for local exchange carriers because the telecommunications industry

operates on the technological frontier, where the unexpected upsets established ways of doing business. Every firm knows that it must be alert to these events; the more aggressive firms will precipitate major changes. How best to organize production will vary among firms. There is, nevertheless, one verity: firms that do not develop organizational and contracting structures that keep them abreast of current and prospective developments will fall behind. The best way for a player today to survive and qualify as a player tomorrow is to achieve real-time responsiveness-

120 Id.

121 In addition, the $\$ 41$ million figure was based on testimony that was submitted by Verizon before the Pennsylvania PUC on a completely different subject matter-namely, appropriate wholesale discounts. See id. ("Verizon had submitted the testimony in an effort to convince the Commission to establish the lowest possible resale discounts for competitors who wished to compete with Verizon by reselling Verizon service.").

122 For a review of the vast literature on transaction cost economics, see OLIVER E. Williamson, The Mechanisms of Governance (1996); and Oliver E. Williamson, THe ECONOMIC INSTITUTIONS OF CAPITALISM (1985). On the application of transaction cost economics to vertical integration, see Martin K. Perry, Vertical Integration: Determinants and Effects, in 1 HANDBOOK OF INDUSTRIAL ORGANIZATION 183, 212 (Richard Schmalensee \& Robert D. Willig eds., 1989). This literature, of course, descends from Ronald H. Coase, The Nature of the Firm, 4 ECONOMICA (n.s.) 386 (1937). 
the capacity for effective and expeditious adaptation .... When parties operate over long time periods in an uncertain environment, successive adaptations of their contractual relationship will be needed. As the contracts in question become more complex and longer in duration, and as the interdependencies between the parties deepen, contracts give way to common ownership with hierarchical management structures. ${ }^{123}$

The transaction costs of negotiating and enforcing contracts make it prohibitively costly to write contracts that specify all obligations under all contingencies. In such circumstances, contracting parties may engage in opportunistic behavior, which undermines the likelihood of maximizing joint profits. ${ }^{124}$

Economists have examined vertical integration in several industries within the transactions-cost framework. To name only a few, economists credit the coordination of investment and production decisions for inducing vertical integration in the petroleum, ${ }^{125}$ aluminum, ${ }^{126}$ automobile parts, ${ }^{127}$ and aerospace industries. ${ }^{128}$ For example, vertical integration increased the return to research and development by facilitating communication between stages of production in the U.S. petroleum industry. ${ }^{129}$ The lesson of transaction costs economics and vertical integration applies with equal force to the decision to engage in retail activities. A direct sales force enables a firm to provide incentives such as security and promotion whereas outside contracting complicates such efficiency-enhancing devices. ${ }^{130}$ Paul Milgrom and John Roberts note:

123 Affidavit of Oliver E. Williamson $\uparrow \uparrow$ 6-7, United States v. Western Elec. Co., Civil Action No. 82-0192 (D.D.C. July 3, 1994) (filed on behalf of several regional Bell operating companies to accompany a motion to vacate the line-of-business restrictions in the Modification of Final Judgment).

124 The classic explanation of this "hold-up" problem is Victor P. Goldberg, Regulation and Administered Contracts, 7 BELL. J. ECON. 426 (1976).

125 See, e.g., DAVID J. TEECE, VERTICAL INTEGRATION AND VERTICAL DIVESTITURE IN THE U.S. OIL INDUSTRY (1976).

126 See, e.g., JOHN STUCKEY, VERTICAL INTEGRATION AND JOINT VENTURES IN THE ALUMINUM INDUSTRY (1983).

127 See, e.g., Benjamin Klein, Robert G. Crawford \& Armen A. Alchian, Vertical Integration, Appropriable Rents, and the Competitive Contracting Process, 21 J.L. \& ECON. 297 (1978); Kirk Monteverde \& David J. Teece, Supplier Switching Costs and Vertical Integration in the Automobile Industry, 13 BELL J. ECON. 206 (1982).

128 See, e.g., Scott E. Masten, The Organization of Production: Evidence from the Aerospace Industry, 28 J.L. \& ECON. 403 (1984).

129 See, e.g., Henry O. Armour \& David J. Teece, Vertical Integration and Technological Innovations, 62 REV. ECON. \& STAT. 490 (1980).

130 See, e.g., Erin Anderson \& David C. Schmittlein, Integration of the Sales Force: An Empirical Examination, 15 RAND J. ECON. 385 (1984). 
In the integrated organization, planning entails consultation between those who sell the product, those who make it, and those who supply parts or systems for it. Together they forecast capacity needs and identify product improvements and investments in specialized equipment that promise higher quality or lower production costs. If the investment is highly specific, vertical integration alleviates the hold-up problem by eliminating the opportunity to negotiate over the price paid to the owner of the newly created asset. ${ }^{131}$

Relative to contracting at arm's length, vertical integration reduces these costs.

This insight from transaction costs economics complements the more abstract results that economists have derived from agency theory and the organizational-incentive theory of the firm, which emphasize the effects of information on the choice between contracting and vertical integration. ${ }^{132}$ Daniel Spulber notes that one motivation for vertical integration is that "[b]y exercising residual control over the firm's investments, the firm improves monitoring of the performance of the firm's divisions ... [and] can coordinate the activities of its divisions, separating or combining investment projects to take advantage of new information about performance or to realize complementarities."

These considerations about transaction costs and imperfect information plainly apply to the telecommunications industry. The fact that no RBOC has voluntarily divested its network operations from its retail activities suggests that the costs of contractual exchange exceed the costs of internal exchange. Moreover, as Williamson notes, the telecommunications industry is constantly evolving, which suggests that contracting for retail sales with an outside party would be prohibitively expensive. Finally, the high-degree of asset specificity-for example, dedicated capital (the loops and equipment that cannot be used in other industries) and brand-name capital-give rise to "appropriable quasirents," which implies that contracting with retail outlets could induce the opportunistic behavior that Milgrom and Roberts note. ${ }^{134}$ In this sense, the telecommunications industry resembles the many other vertically

131 Paul Milgrom \& John Roberts, ECONOMics, ORganization and MaNagement 558 (1992).

132 See, e.g., Michael H. Riordan \& David E. M. Sappington, Information, Incentives, and Organizational Mode, 102 Q.J. ECON. 243 (1987). The literature is surveyed in DANIEL F. SPULBER, MARKET MICROSTRUCTURE: INTERMEDIARIES AND THE THEORY OF THE FIRM 289-306 (1999).

133 Id. at 306.

134 See Klein, Crawford \& Alchian, supra note 127. 
integrated industries whose structure economists have analyzed from the perspective of transaction costs.

\section{Accountability for Product Quality}

Quality assurance is a significant benefit from vertical integration in the telecommunications industry. Vertical integration is a response to the difficulty of reliably specifying and measuring contractual performance. ${ }^{135}$ Professor Armen Alchian explains: "Sometimes it may be too costly to determine the quality of one of the inputs objectively, and if the quality of the input cannot be costlessly inferred from the quality of the finished product, vertical integration can align [the companies'] interests better."136 A cost of vertical separation is the loss of a single point of accountability. It is difficult for a customer to hold multiple vendors accountable for some form of product failure. Without this single point of accountability, consumers are left "calling firms' service departments and searching for the party responsible for the failure."137

\section{Bundled Offerings}

Vertical integration allows firms to combine final services. The question is not whether consumers are incapable of bundling end services on their own. Clearly, they can do so, but at a cost. The relevant question, rather, is whether firms or consumers are the more efficient integrators of services and functionalities. ${ }^{138}$ It would seem self-evident in a technologically dynamic market such as telecommunications that firms are the more efficient integrators. If that assumption is correct, then, for similar reasons, a vertically integrated retailer would have an inherent cost advantage over a non-integrated retailer when offering consumers a bundle of complementary telecommunications functionalities or services. Mandatory structural separation would erase the ILECs' cost advantage as integrators of telecommunications services, which, as we explain more fully in Part IV, explains the appeal of this regulatory intervention to the CLECS.

If there were not significant efficiencies from vertical integration in the provision of telecommunications services, the interexchange carriers

135 See Armen A. Alchian, Vertical Integration and Regulation in the Telephone Industry, 16 MANAGERIAL \& DECISION ECON. 323, 323-26 (1995)

136 Id.

137 Id. at 325.

138 J. Gregory Sidak, An Antitrust Rule for Software Integration, 18 YALE J. ON REG. 1, 30 $31,45-46,68-69$ (2001) (discussing whether the consumer or the producer is the lower-cost integrator of software functionalities). 
(which, today, are the largest CLECs) would not have acquired or built their own fiber rings in metropolitan markets, ${ }^{139}$ nor would they have acquired cable MSOs and wireless carriers or spectrum licenses. Professors Michael T. Maloney and Robert E. McCormick found empirical evidence in the mid-1990s of the value of vertically integrated telecommunications services. They performed an event study of the announcement of MCI's decision to enter the local market and the announcement of AT\&T's acquisition of McCaw Cellular, then the largest wireless carrier. ${ }^{140}$ They found that vertical corporate alignments between interexchange carriers and wireless carriers produced positive abnormal returns for the companies involved, ${ }^{141}$ whereas the RBOCs, which at the time could not engage in such integration because of the line-of-business restrictions in the MFJ, ${ }^{142}$ experienced substantial negative abnormal returns. ${ }^{143}$ This finding suggests the kind of loss in market value that mandatory structural separation would likely impose on the ILECs, a substantial portion of which would surely translate into diminished consumer welfare because of lost productive efficiencies.

Professors Maloney and McCormick also emphasized the high costs of billing, which can be spread across multiple services through vertical integration. ${ }^{144}$ By bundling services and billing on a monthly or annual fixed fee, a vertically integrated carrier could significantly reduce its billing costs. ${ }^{145}$ Negotiating contracts to allocate the revenues shared between companies that supply different portions of the billed services would eliminate those cost savings. ${ }^{146}$ Structural separation of the ILECs would necessitate the negotiation of such contracts.

\section{The Division of Indivisible Assets}

The vertically integrated ILECs have significant capital in intangible assets such as customer loyalty and goodwill. For example, Verizon

139 See Alchian, supra note 135, at 326; see also Michael T. Maloney \& Robert E. McCormick, Realignment in Telecommunications, 16 MANAGERIAL \& DECISION ECON. 401 (1995).

140 Id. at 423 n. 20.

141 Maloney and McCormick found that the combined portfolio of AT\&T and McCaw Cellular gained $4.04 \%$, or $\$ 2.52$ billion, over the two-day merger event window, while the value of the RBOCs fell by $1.92 \%$, or $\$ 2.53$ billion. Id. at 408 . For the second event, MCI's value rose by $\$ 608$ million, or $4.41 \%$, on its announcement, while the combined value of the RBOCs fell by $\$ 7.97$ billion, or $4.88 \%$. Id. at $412-13$.

142 See Paul W. Macavoy, The FaILURE of ANTITRUST AND REgulation to Establish COMPETITION IN LONG-DISTANCE TELEPHONE SERVICES 196-200 (1996).

143 Maloney \& McCormick, supra note 139, at 417-18.

144 Id. at 419.

145 Id.

146 See id. 
reported $\$ 41.9$ billion in intangible assets as of December $2000,{ }^{147}$ including goodwill, wireless licenses, and customer bases. ${ }^{148}$ Mandatory structural separation would force the ILECs to allocate indivisible or intangible assets of local operating companies across its new subsidiaries. But there is no obvious way to divide indivisible, intangible assets such as intellectual property and brand names. Under mandatory structural separation, would Verizon's wholesale company or retail company own the rights to use the Verizon name in a particular state? Or would both companies share the right? Could regulators lawfully deny Verizon's retail company the use of its own brand name (as state PUCs have considered ordering in restructuring proceedings to affect retail competition in the electric power industry $\left.{ }^{149}\right)$ ? Merely to pose such questions is to underscore the inherent inefficiency of dividing assets that a firm uses in common across two or more of its productive sequences and which, therefore, give rise to economies of scope.

\section{Enforcement Costs}

Structural remedies have substantial enforcement costs, particularly in technologically dynamic network industries. ${ }^{150}$ The most pertinent example is the AT\&T divestiture, which was a federal antitrust case rather than an FCC proceeding. ${ }^{151}$ As noted earlier, the MFJ prohibited the RBOCs from providing interLATA long-distance service and from

147 VERIZON COMMUNICATIONS INC., 2001 SEC FORM 10-K405, at F-24 (Mar. 23, 2001).

148 Id. at F-28.

149 See, e.g., Application of Pennsylvania Electric Company for Approval of Restructuring Plan Under Section 2806 of the Public Utility Code, No. R-00974009, R-00974009C0001, R00974009C0002, Pa. Pub. Util. Comm'n, June 30, 1998, $1998 \mathrm{~Pa}$. PUC LEXIS 162 (opinion and order). With respect to the restructuring of an electric utility into a generation company and an electric distribution company ("EDC"), the Pennsylvania PUC rejected a

proposed bar on the ability of affiliated suppliers or divisions to use the EDC brand name in marketing. We are not inclined to impose this restriction ... . [A]n EDC may not allow its competitive affiliate to use its name to suggest that the EDC would provide better distribution services if power is purchased from its affiliate. Similarly, it would be inappropriate for the competitive affiliate to use the EDC name to indicate that supply purchased from other competitors may be less reliable or that the generation services are in fact being provided by the EDC. We continue to believe that an absolute bar on the competitive affiliate's use of the EDC brand name in marketing is not necessary or desirable. Rather, we are satisfied that restrictions on the manner in which the EDC brand name is used by the competitive affiliate are sufficient to ensure a level playing field among market participants.

Id. at *322-*23 (citation omitted).

150 See Robert W. Crandall, The Failure of Structural Remedies in Sherman Act Monopolization Cases, 80 OR. L. REV. 109 (2001); Howard A. Shelanski \& J. Gregory Sidak, Antitrust Divestiture in Network Industries, 68 U. CHI. L. REV. 1, 6-15 (2001).

151 United States v. Am. Tel. \& Tel. Co., 552 F. Supp. 131 (D.D.C. 1982), aff'd sub nom. Maryland v. United States, 460 U.S. 1001 (1983) [hereinafter Modification of Final Judgment]. 
manufacturing telecommunications equipment. But what constituted "manufacturing" or "interLATA transport"? Defining such terms and enforcing the entry restrictions based upon them invited strategic use of litigation by the parties to the decree. The social costs of that strategic litigation were surely profound, particularly in light of the rapid technological change occurring in telecommunications at the time. ${ }^{152}$

The litigation over the MFJ is a vivid example of the subversion of the antitrust process for rent-seeking objectives. The experience illustrates that structural remedies that incorporate supervisory and behavioral elements can be costly. The point holds regardless of whether the structural remedy is styled as regulation or antitrust. ${ }^{153}$ In particular, the MFJ provided a waiver process by which the RBOCs could request the court's permission to enter new markets. Under Section VIII(C) of the decree, the RBOCs were entitled to have a particular line-of-business restriction lifted if they could show that "there [was] no substantial possibility" that a BOC could use its monopoly power to impede competition in the market that it proposed to enter. ${ }^{154}$ But the waiver process was painfully slow. ${ }^{155}$ The ostensibly straightforward AT\&T consent decree, in fact, became a suffocating layer of new regulation for the telecommunications industry. ${ }^{156}$

\section{The Inefficacy of Mandatory Structural Separation}

Even if one accepts, for the sake of argument, that anticompetitive behavior by the ILECs has been responsible for the failure of certain

152 See Hausman \& Sidak, supra note 81, at 428-29 (documenting delay in court rulings on requested waivers of the line-of-business restrictions).

153 Skepticism of mandatory structural separation is also justified on the basis of the limited success of divestiture remedies secured by the government, under Section 2 of the Sherman Act, in numerous cases outside the telecommunications industry in which courts found that a firm or groups of firms had monopolized a market. The conventional wisdom is that in most of these cases the structural remedies were at least partially successful in restoring competition. In actuality, little evidence supports such a view. See Crandall, supra note 150; Shelanski \& Sidak, supra note 150, at 39-57. Indeed, in most cases the available evidence does not enable one to conclude that the court-imposed relief had its intended effect, or that a less costly behavioral remedy would not have been as efficacious.

154 Modification of Final Judgment, supra note 151 , $\$$ VIII(C).

155 In 1993, the average waiver request had been pending for thirty-six months even though the Department of Justice opposed relief in only four of the 266 requests. See Paul H. Rubin \& Hashem Dezhbakhsh, Costs of Delay and Rent-Seeking Under the Modification of Final Judgment, 16 MANAGERIAL \& DECISION ECON. 385, 385-87 (1995). By 1994, the backlog period had grown to 54.7 months, although the court approved $96 \%$ of the waiver requests. Id. at 387-89.

156 See MACAVOY, supra note 142; J. GREGORY SIDAK \& DANIEL F. SPULBER, DEREGULATORY TAKINGS AND THE REGULATORY CONTRACT: THE COMPETITIVE TRANSFORMATION OF NETWORK INDUSTRIES IN THE UNITED STATES 56 (1997). 
CLECs, it does not follow that mandatory structural separation would be an efficacious remedy.

\section{The Absence of Systematic Evidence of Discrimination}

It is not clear how mandatory structural separation would protect against any allegedly discriminatory practices by the ILECs in the provisioning of UNEs or the transferring of resale customers. Such a prescription is not supported by any evidence. Before regulators can design a policy to deter "discrimination" against CLECs, the CLECs ought to produce credible evidence that discrimination exists. Neither AT\&T nor any other CLEC had documented any systematic abuse by an ILEC in provisioning facilities. A collection of anecdotes concerning the timeliness of provisioning does not amount to systematic evidence of discrimination against the CLECs.

For example, the Pennsylvania PUC did not chronicle any systematic evidence of discrimination in its early decision to mandate structural separation. 157 The closest example of "discrimination" that the Pennsylvania PUC described in its Global Order concerned the timeliness in the provisioning of collocation by Verizon's local operating company, Bell Atlantic-Pennsylvania ("BA-PA"):

Significant delays in providing collocation can severely hamper the operations of CLECs and delay competition in Pennsylvania. BA-PA's Tariff No. 218 establishes a "standard interval" for physical collocation of 120 business days, or nearly six (6) months calendar time. This is an inordinately long period. In their petitions in this proceeding, BA-PA and the CLECs suggest a ninety (90)-day provisioning interval. [Accelerated Connections Inc.] has recommended that this Commission adopt a sixty (60) calendar-day interval for traditional physical collocation and thirty (30) calendar days for cageless or common collocation arrangements. ${ }^{158}$

The PUC eventually decided that Bell Atlantic-Pennsylvania should "provide for a ninety (90)-calendar-day maximum provisioning interval from the date BA-PA receives a deposit on collocation space from a CLEC to the date when BA-PA's work is completed."159

If the Pennsylvania PUC can directly control the timeliness of the ILEC's provision of collocation down to the number of days, then why is mandatory structural separation necessary to ensure the ILEC's

157 Pennsylvania Global Order, supra note 9, §XVI.

158 ld. at 92 (internal citation omitted).

159 Id. 
nondiscriminatory treatment of the CLECs? Plainly, the Pennsylvania commission already wields a more finely tuned policy instrument.

\section{The Ability of Behavioral Restraints to Prevent Discrimination}

Even a vertically integrated local service provider might find it more profitable to use resellers to reach niche markets than to address those markets by itself, particularly if the wholesale prices are set at appropriate levels. Hence, in addition to bearing the burden to show systematic evidence that discrimination has actually occurred, the CLECs ought to show that the ILEC benefits from the discrimination and that a structurally separate wholesaler of network access would have different incentives with respect to the treatment of the CLECs.

Finally, if discrimination against CLECs were the problem that AT\&T claims, then why have the ILECs not employed it to disadvantage their wireless rivals? The market shares of non-BOC wireless carriers (52\%) represent undisputable evidence of a lack of discrimination by RBOCs against unaffiliated wireless rivals. ${ }^{160}$ Even if it wanted to discriminate, a vertically integrated cellular or personal communications services ("PCS") provider that owned a local exchange network could not do so because regulators closely monitor interconnection rates. As a result, the ILECs have not used wireless-to-wireline interconnection in a discriminatory fashion against unaffiliated PCS providers or unaffiliated CLECs. There is no empirical evidence that its integrated position has allowed the ILEC's affiliated wireless carrier to obtain a larger market share than its unintegrated rivals. ${ }^{161}$ It is premature to devise remedies for a problem that has not been shown to exist.

\section{The Inability of Mandatory Structural Separation to Lower} Wholesale Discounts

With respect to lowering wholesale discounts, Mr. Armstrong's comparison of mandatory structural separation of the RBOCs to the AT\&T divestiture is flawed for at least four reasons. First, the consent decree in the government's divestiture case against the Bell System did not require AT\&T to separate its wholesale long-distance business from its retail longdistance business. Rather, the MFJ mandated divestiture of the local-

160 Sixth Report on Commercial Mobile Services, supra note 111, app. C, tbl.3. Market shares are for end of year 2000 .

161 See, e.g., Fred S. McChesney, Empirical Tests of the Cross-Subsidy and Discriminatory Access Hypotheses in Vertically Integrated Telephony, 16 MANAGERIAL \& DECISION ECON. 493 (1995). 
exchange facilities of the former Bell System from its long-distance facilities; further, it prohibited, among other things, the RBOCs from providing long-distance service from one local access and transport area ("LATA") to another, and from manufacturing telecommunications equipment. ${ }^{162}$ Hence, the decline in wholesale rates charged by AT\&T to unaffiliated long-distance resellers cannot possibly be attributed to the structural separation (indeed, the complete divestiture) of the former Bell System. ${ }^{163}$

Second, when judging the competitiveness of a market, regulators and legislators should be more concerned about the margins between prices and incremental costs than about the size of discounts available from those prices. Professor Paul W. MacAvoy has found that the price-cost margins earned by the three major long-distance providers on discount plans were increasing during the 1990s - that is, discount plans did not push margins down. ${ }^{164}$ Moreover, the cost of marketing long-distance services is a large share of any carrier's (including AT\&T's) total costs. Therefore, wholesale discounts are likely to bulk large in these services. Mr. Armstrong surely recognizes that the ILECs' rates for local exchange service are not significantly above long-run marginal costs-if indeed those rates even cover costs for large segments of customers. ${ }^{165}$ Until costs are properly taken into account, it does not make sense to compare discounts on prices across two different products-long-distance and local exchange.

Third, the Pennsylvania PUC recently demonstrated that mandatory structural separation of the ILECs is not necessary to lower the regulated wholesale rates in the local services market. On March 22, 2001, the Pennsylvania PUC ordered a $4.4 \%$ reduction in the unbundled loop rate in density zone four, which covers most rural areas of the state. ${ }^{166}$ Because the Pennsylvania PUC has the discretion to increase the ILEC's resale discount and lower the price of its unbundled loop, the entire question of mandatory structural separation remains irrelevant to lowering the ILEC's wholesale rates.

Fourth, it defies the economic logic of input pricing to suppose that mandatory structural separation would lower the prices charged a CLEC

162 Modification of Final Judgment, supra note 151, at 226-34. See generally MICHAEL K. KellogG, JoHN ThORNe \& Peter W. HUber, Federal TeleCOMmUNications LaW 199-248 (1992)

163 For an economic analysis of the AT\&T divestiture and its aftermath, see ROBERT W. CRANdall, After the BREAKuP: U.S. TeleCOMMUNICATIONS IN A MORE COMPETITIVE ERA (1991).

164 MacAvoy, supra note 94, at 305; see also MACAVoY, supra note 142.

165 See generally CRANDALL \& WAVERMAN, supra note 92, at 166 (discussing regulatory requirements to price local exchange service below cost).

166 Pa. PUC Orders Functional Separation of Verizon, Not Full Breakup, COMM. DALLY, Mar. 23, 2001; Pennsylvania Global Order, supra note 9. 
by a hypothetically unregulated ILEC. ${ }^{167}$ Simply splitting the wholesale and retail operations of a firm would not eliminate the market power of the wholesale unit with respect to rival retail firms. If one assumes, as AT\&T alleges, that an ILEC has monopoly power in local exchange services, then it necessarily follows that the wholesale division of that ILEC would have monopoly power in the nonsubstitutable wholesale inputs required to produce local exchange services. (Certainly, retailing inputs are not a source of monopoly power.) Basic price theory implies that the (unregulated) wholesale division would charge all retailers (each in effect would be unaffiliated after mandatory structural separation) the monopoly price for the input. ${ }^{168}$ But integrated or not, an ILEC obviously does not unilaterally set the wholesale prices at which it sells inputs to competitors. To the contrary, those wholesale prices are regulated rates that must receive the prior approval of a state PUC pursuant to its duties under Section 252(d)(3) of the Telecommunications Act of 1996. ${ }^{169}$ How could mandatory structural separation possibly lower regulated wholesale rates that are set according to TELRIC-based prices or the avoided cost of retailing? Mr. Armstrong does not provide an answer. ${ }^{170}$

\section{The Unsatisfactory or Inconclusive Experience with Structural Separation}

The experience with structural separation has been unsatisfactory or inconclusive. The FCC has mandated structural separation in several situations that are distinguishable from local exchange

167 See BAUMOL \& SIDAK, supra note 118 ; SIDAK \& SPULBER, supra note 143, at 20; William J. Baumol, Janusz A. Ordover \& Robert D. Willig, Parity Pricing and Its Critics: A Necessary Condition for Efficiency in the Provision of Bottleneck Services to Competitors, 14 YALE J. ON REG. 145 (1997); William J. Baumol \& J. Gregory Sidak, The Pricing of Inputs Sold to Competitors, 11 YALE J. ON REG. 171 (1994).

168 See Jean Tirole, The Theory of Industrial Organization 182 (1988)

16947 U.S.C. $\$ 252$ (d)(3) (2002) ("Wholesale prices for telecommunications services.-For the purposes of Section 251 (c)(4), a State commission shall determine wholesale rates on the basis of retail rates charged to subscribers for the telecommunications service requested, excluding the portion thereof attributable to any marketing, billing, collection, and other costs that will be avoided by the local exchange carrier.").

170 As Professor Jean Tirole notes, a competitive retail sector for local service would push down retail rates to their marginal cost, which happens to be the monopoly input price plus the retailing costs of a non-facilities-based lessee of ILEC facilities. TIROLE, supra note 168 , at 182 . Stated differently, the classic double-marginalization problem disappears because downstream competition eliminates the second margin. Unfortunately, under reasonable assumptions, the retail price under vertical disintegration and downstream competition may exceed the retail price under vertical integration. For example, any differentiation among retail firms could allow the (partial) return of the double-marginalization problem-that is, when consumers have different tastes or are located in different areas, retail local services firms would have the ability to add a second margin to the wholesaler's (monopoly) price. Id. 
telecommunications. The same agency has tried and rejected mandatory structural separation in another setting.

\section{a. The American Experience with the AT\&T Divestiture and the Canadian Alternative}

It is often assumed that competition in the U.S. long-distance market could not develop until Judge Harold Greene dismembered AT\&T, separating the local "bottleneck" facilities from the long-distance and manufacturing operations in the 1982 antitrust decree. But vertical divestiture-the ultimate form of structural separation - was not necessary to accomplish this result. No other country has forced such vertical divestiture on its incumbent telephone company. For example, the Canadian regulatory and competition authorities did not attempt to force vertical divestiture on the Canadian incumbents-Bell Canada, TELUS, BC Tel (now part of TELUS), MT\&T, Island Telephone, and NewTel. Despite the fact that all continue to offer both local and long-distance service, longdistance competition has developed more rapidly in Canada than in the United States. ${ }^{171}$

The Canadian approach to facilitating entry relies not on structural separation but on simple equal-access requirements for competitive carriers. The Canadian Radio-television and Telecommunications Regulatory Commission ("CRTC") learned from a critical U.S. error-the failure of regulators to mandate equal access to local switches. The FCC had such an opportunity in 1969 (when MCI was first allowed to enter as a private-line carrier), in 1971 (when private-line entry was allowed generally), and in 1977 (when the courts pried open all long-distance services), but the agency declined to take them. Equal access for all longdistance carriers became a reality only when it was mandated by the 1982 decree that broke up AT\&T and was subsequently extended to non-Bell local exchange companies by the FCC. Compliance was generally not achieved until 1986-87, more than a decade after MCI began offering ordinary (switched) long-distance service. In contrast, the CRTC required that incumbent carriers provide equal access to all certified entrants in its 1992 order opening the long-distance market to competition. This requirement would quickly unleash long-distance competition.

The United States began to admit competition into long-distance services nearly twenty-five years ago. Canada began much more recently,

171 This discussion is based on a more extensive analysis of U.S. and Canadian competition in Robert W. Crandall \& Thomas W. Hazlett, Telecommunications Policy Reform in the United States and Canada, in TELECOMMUNICATIONS LIBERALIZATION ON TWO SIDES OF THE ATLANTIC 8 (Martin Cave \& Robert W. Crandall eds., 200I). 
waiting until 1992 to allow facilities-based competition. Nevertheless, Canada's long-distance market is now at least as competitive as that of the United States. The U.S. long-distance market has become much less concentrated since MCI ventured forth in the mid-1970s. Because U.S. local carriers were not required to offer equal access to long-distance carriers until AT\&T was broken up by consent decree, most analyses of U.S. long-distance competition begin with 1984.

Despite its late start, long-distance competition in Canada is well advanced. Spared from the contentious court debates that clouded the U.S. environment and proceeding much more deliberately in implementing equal access, the Canadians have avoided much of the transition required in the United States to move from monopoly to a more competitive market. Indeed, because Canada did not pursue vertical divestiture, the incumbent local companies are aggressive competitors with a shadow price of access that is equal to marginal cost. Within six years of Canada's long-distance decision, the incumbent companies had lost about $35 \%$ of their market shares. In the United States, AT\&T's market share fell from $84 \%$ of interstate minutes in the third quarter of 1984 to $65 \%$ in 1989 , five years after divestiture and about fourteen years after MCI began to offer switched long-distance service. These results suggest that an equal-access regime without divestiture can work well to assure entry into long-distance services.

Ultimately, any judgment about the degree of competition is based on the proximity of rates to incremental cost. Access charges are now similar in Canada and the United States, yet Canadian long-distance rates have fallen below those in the United States. Equal access and the ability of the incumbent local carriers to compete aggressively appear to be sufficient to generate results that now surpass those in the United States more than twenty years after MCI began offering switched long-distance service. This result strongly suggests that it was not vertical divestiture, but equal access, that created the environment for long-distance competition.

\section{b. Advanced Services}

The FCC has imposed structural separation for "advanced services" supplied by ILECs, which the agency defines as "wireline, broadband telecommunications services, such as services that rely on digital subscriber line technology (commonly referred to as xDSL) and packet- 
switched technology." 172 The alternative to operating a separate advanced services subsidiary is not that the ILEC is barred from supplying advanced services; rather, the advanced services supplied by the ILEC would be subject to the existing regulation applicable to ILECs. For this reason, the FCC calls the separate subsidiary for advanced services an "optional alternative pathway for incumbent LECs that would allow separate affiliates to provide advanced services free from incumbent LEC regulation." 173 The FCC deems such an affiliate to be exempt from unbundling obligations and would be considered nondominant, such that it would be exempt from price-cap or rate-of-return regulation and the obligation to file tariffs. ${ }^{174}$

Several factors distinguish the FCC's policy on advanced-services separate affiliates from the proposals for mandatory structural separation of the ILECs. First, the policy is voluntary and offers a quid pro quo. In return for grouping its newer, broadband services in a separate affiliate, the ILEC receives regulatory relief and thus reduces uncertainty concerning the returns to investment in broadband technology. This form of separation may nonetheless impose costs of the sort described above, but it is the ILEC's decision whether those costs are greater or less than the costs associated with unbundling requirements and dominant-carrier regulation.

Second, because advanced services are, by definition, more technologically advanced than narrowband services (such as traditional voice telephony), the ILEC may have fewer sunk costs at risk from structural separation of the former compared with structural separation of the existing local network into retail and wholesale entities. That is not to say, of course, that advanced services will require a high degree of coordination of production and investment. The separate-affiliate requirement may distort investment choices away from technologies having high sunk costs to those having relatively less sunkeness in their cost structures.

Third, given the substantial lead that cable modems have over DSL services supplied by ILECs, it is questionable whether the separateaffiliate path for advanced services has produced its intended benefits. As of early 2002 , DSL appears to be losing the race. ${ }^{175}$

172 Deployment of Wireline Services Offering Advanced Telecommunications Capability, 13 F.C.C.R. 24,011, \3, at 24,014 (1998) (memorandum opinion and order and notice of proposed rulemaking).

173 Id. $\$ 19$, at 24,020

174 Id.

175 See Jerry A. Hausman, J. Gregory Sidak \& Hal J. Singer, Cable Modems and DSL: Broadband Internet Access for Residential Customers, 91 AM. ECON. ASS'N PAPERS \& PROC. 302 (2001); Jerry A. Hausman, J. Gregory Sidak \& Hal J. Singer, Residential Demand for Broadband 


\section{c. Wireless}

The FCC requires ILECs to establish structurally separate affiliates for wireless services. This requirement, however, is distinguishable from mandatory structural separation on several grounds. First, it is easier to segregate the assets necessary to provide wireless service from those necessary to provide local wireline service than it is to separate supposedly "wholesale" wireline assets from supposedly "retail" wireline assets. Second, the separation of wireless from wireline operations served the strategic objectives of ILECs in the sense that wireless had very different characteristics of demand growth and capital investment from those of the wireline network. Accordingly, as the voluntary divestiture of AirTouch from Pacific Telesis attests, there were efficiencies in presenting a "pure play" to the capital markets. There is no realistic expectation that mandatory structural separation of the ILECs would unleash unexploited opportunities for the superior capitalization of local exchange carriers.

\section{d. Voluntary and Unsolicited Plans for Structural Separation}

One American telephone company attempted a form of structural separation before the Telecommunications Act of 1996. A large foreign telecommunications company has rebuffed unsolicited offers to buy its local network infrastructure. Both experiences are instructive and underscore why current proposals for mandatory structural separation are unlikely to increase economic welfare.

\section{i. Voluntary Structural Separation: Rochester Telephone}

In February 1993, Rochester Telephone filed a proposal with the New York State Public Service Commission ("NYPSC") to open its Rochester, New York local exchange market to competition. After seven months of public hearings, the NYPSC approved a joint stipulation outlining Rochester Telephone's voluntary structural separation. ${ }^{176}$ The joint

Telecommunications and Consumer Access to Unaffiliated Internet Content Providers, 18 YALE J. ON REG. 129 (2001).

176 See Petition of Rochester Telephone Corporation for Approval of Proposed Restructuring Plan, Petition of Rochester Telephone Corporation for Approval of a New Multi Year Rate Stability Agreement, Case 93-C-0103, N.Y. Pub. Serv. Comm'n, Nov. 10, 1994, 1994 N.Y. PUC LEXIS 64, *3 [hereinafter Rochester Restructuring Order]. Signatories to the joint stipulation were Rochester Telephone, the Department of Public Service staff, Time Wamer Communications, the Communications Workers of America, AFL-CIO, the New York State Telephone Association, the New York State Department of Economic Development, and the Public Utility Law Project of New York. 
stipulation established an "Open Market Plan" ("OMP") with two major components. First, the Open Market Plan "reinvented" Rochester Telephone by creating (1) a holding company (Frontier Corporation) that controlled the stock in each of Rochester Telephone's newly created subsidiaries, (2) a regulated ILEC (Rochester Telephone Corporation, or "RTC"), and (3) a "lightly" regulated CLEC (Frontier Telecommunications of Rochester, or "FTR"). Second, the joint stipulation drafted a regulatory plan for the period January 1, 1995 through December $31,2001 .{ }^{177}$ The regulatory plan addressed rates (including a revenue requirement), service quality (network and customer service), and enhancement of competition. On January 1, 1995, Frontier Communications began operating as the umbrella corporation for its structurally separated telecommunications subsidiaries. The holding company hoped that its voluntary restructuring would position the company to compete in "the market on our own terms."178

In its 1994 Rochester Restructuring Order, the NYPSC said that it generally opposed holding company reorganization efforts because they make complex regulatory processes even more unruly. ${ }^{179}$ The NYPSC knew that its approval of Rochester Telephone's voluntary structural separation would lead to lengthy regulatory proceedings, but it also hoped the expected procompetitive benefits of the reorganization would outweigh the costs. After numerous reconsiderations of its rate-setting procedures for regulated holding companies, however, the NYPSC became frustrated: " $[\mathrm{T}]$ he joint stipulation and agreement embodying the Open Market Plan is a complex, interrelated package that allowed FTR to form a holding company, a request that was denied many times in the past."

The structural separation plan soon encountered difficulties. In 1996 and 1997, Frontier failed to meet the minimum acceptable service quality

177 Id. at *11-*12; see also INGO VOGELSANG \& BRIDGER M. MITCHELL, TelecommuniCations Competirion: THE LAST TEN Miles 194 (1997) (FTR "provid[es] retail services in competition with other companies and buy[s] wholesale services from Rochester Telephone at regulated prices. Local competitors are thus able to select services from Rochester Telephone and combine them with their own service elements and equipment."). One of the authors of this Article supplied an affidavit with Alfred E. Kahn on behalf of Rochester Telephone, supporting the plan.

178 Vince Vittore, Rochester Tel: Blueprint for Change, 99 TEL. ENG'R \& MGMT. 24 (1995) (quoting Paul Solinski, Rochester Telephone's corporate planning and regulatory policy director).

179 Rochester Restructuring Order, supra note 176, at *15-*16 ("In the past, we have favored holding company ownership of a utility only in limited circumstances, particularly where the utility is small and benefits from affiliation with others through increased ability to raise capital and increased opportunity for cost savings through economies of scale. In general, however, we have concluded that stand-alone operation of a utility is superior to a holding company structure.").

180 Complaint of AT\&T Corp., Opinion and Order on Unbundled Network Elements Thoroughfare Guide, and Legal Services Petition, Case 95-C-0657, at 7-8, N.Y. Pub. Serv. Comm'n, July 22, 1999. 
measurements established by the Open Market Plan. ${ }^{181}$ The NYPSC levied more than $\$ 1$ million in fines against Frontier Telephone for missing its performance benchmarks. ${ }^{182}$

Voluntary structural separation does not mean that CLECs will desist from seeking large wholesale discounts from ILECs. When the NYPSC approved Rochester Telephone's restructuring plan, the commission approved the company's wholesale discount rate of $5 \% .{ }^{183}$ However, the NYPSC noted that the $5 \%$ wholesale discount rate was "a starting point," and the commission invited comments on the appropriateness of its pricing structure. ${ }^{184}$ In 1996, after receiving numerous complaints and petitions from CLECs, the NYPSC revised Rochester Telephone's wholesale discount rate to $13.5 \% .{ }^{185}$ AT\&T continued to protest that Rochester Telephone's wholesale discounts were still too low: AT\&T submitted an avoided-cost study and requested wholesale discount rates between 20.4 and $24.5 \%{ }^{186}$ After accepting AT\&T's cost study, the NYPSC again increased Rochester's wholesale discount rates to $17 \%$ if it provided operator services and $19.6 \%$ if the reseller provided operator services. ${ }^{187}$

Voluntary structural separation also does not mean that it will be easier for CLECs to move local telephony customers from the ILEC. In its Local Competition First Report and Order, the FCC explained how Rochester Telephone's structural separation complicated the implementation of the resale requirements in the Telecommunications Act of 1996:

AT\&T and TCC commented on AT\&T's experience in the Rochester, New York market as a reseller of Rochester Telephone's services under Rochester Telephone's Open Market Plan. Parties noted that AT\&T was required to submit a detailed order form, initially through a facsimile machine and later through e-mail, in order to resell Rochester Telephone services. AT\&T asserts that it was signing up between one and two hundred new customers daily and therefore had to fax up to 1400 pages daily to Rochester Telephone. AT\&T and TCC contend that such a

181 Petition of Rochester Telephone Corp., Order Approving Proposed Modifications to the Open Market Plan, Case 93-C-0103, N.Y. Pub. Serv. Comm'n, Oct. 16, 1998.

182 Petition of Rochester Telephone Corp. for Approval of a New Multiyear Rate Stability Agreement, Case 93-C-0033, N.Y. Pub. Serv. Comm'n, Nov. 6, 1997 (Order Directing Rebates).

183 Id. at 34-35.

184 Id. at 27.

185 Petition of Rochester Telephone Corp. for Approval of a Proposed Restructuring Plan, Case 93-C-0103, Opinion No. 96-19, at 21, N. Y. Pub. Serv. Comm'n, July 18, 1996.

186 Complaint of AT\&T Communications of New York, Inc., Case 95-C-0657, Opinion No. 96-30, at 20, N.Y. Pub. Serv. Comm'n, Nov. 27, 1996.

187 Id. at 1. 
manual process is clearly discriminatory and in violation of the 1996 Act because it creates additional delay and the potential for human error, resulting in customer dissatisfaction. TCC argues further that such a disparity in systems allows for the incumbent LEC to schedule service commencement and issue new phone numbers during the initial contact with a customer, while the competitor, at best, must put the customer on hold while it calls the incumbent LEC to obtain such information. ${ }^{188}$

With the benefit of hindsight, it is clear that structural separation of Rochester Telephone did nothing to eliminate the need for more efficient processes for transferring customers from the ILEC to the CLEC. This issue, of course, emerged after the Telecommunications Act of 1996 as the principal complaint upon which AT\&T and others opposed Bell company entry into in-region interLATA long-distance service: AT\&T asserted that the BOC's systems for switching local customers to CLECs were inadequate. Yet, by April 2002, the state PUCs and the FCC had authorized BOC entry in ten states ${ }^{189}$-and in none of those cases had the BOC structurally separated its local exchange operations into wholesale and retail entities. Clearly, Rochester Telephone's experience demonstrated that structural separation was neither a necessary nor a sufficient condition for expeditious CLEC entry.

Before the passage of the Telecommunications Act of 1996, Rochester's joint stipulation imposed limited unbundling requirements on the company: "The only specific network elements the OMP requires FTR to make available to telecommunications carriers are links and ports." After the 1996 legislation, a large part of the company's agreement with the NYPSC was rendered moot because the Telecommunications Act significantly lengthened the list of network elements that Rochester was obliged to provide to CLECs on an unbundled basis.

Rochester Telephone's structural separation was primarily premised on the enhancement of competition. However, six years later the NYPSC observed that "competition ha[d] yet to develop to any noticeable extent."191 Rochester's experiment with voluntary structural separation

188 Local Competition First Report and Order, supra note 96, ๆ 508, at 15,754-55 (footnotes omitted).

189 See supra notes 93-95 and accompanying text.

190 N.Y. DEPT. PUB. SERV., STAFF REPORT ON FRONTIER TELEPHONE OF ROCHESTER INC.'S Unbundled NetWork Elements, THOROUGHFARE GUIDE, AND LEGAL SERVICES PETITION 3 (Apr. 20,1998).

191 Petition of Rochester Telephone Corporation for Approval of Multi-Year Rate Stability Agreement, Case 93-C-0033, 93-C-0103, N. Y. State Pub. Serv. Comm'n. 
ended when Global Crossing bought the company in $1999 .{ }^{192}$ That experiment suggests that voluntary structural separation is not efficacious for developing competition in local telephony.

ii. Unsolicited Private Proposals for Structural Separation: Offers for BT (British Telecom)

In addition to government-mandated structural separation and strictly voluntary structural separation, a third alternative has arisen. A third party can present an unsolicited proposal for corporate reorganization. The proposal could take the form of an unsolicited offer to buy an ILEC's network infrastructure, or it could take the form of an unsolicited corporate control transaction that would subsequently affect a strategy of structural separation or divestiture.

In the United Kingdom, British Telecom ("BT") received two separate and unsolicited offers in 2001 to divest its fixed-line business. Since Oftel, the U.K. telecommunications regulator, began requiring BT to unbundle its local loops in November 1999, BT's competitors have complained that BT has been slow to open its loops. ${ }^{193}$ Despite mounting regulatory pressure to accelerate its local loop unbundling ("LLU") efforts, and despite mounting debt, BT rejected both offers to exit the wholesale telecommunications business altogether. ${ }^{194}$

At the end of July 2001, a United States-based consortium offered British Telecom $£ 8$ billion to buy BT's local loops through a bid vehicle called Earthlease. ${ }^{195}$ Oftel endorsed Earthlease's proposal because the consortium promised to invest $£ 500$ million annually for at least seven years to accelerate the deployment of broadband services. ${ }^{196}$ BT rejected Earthlease's bid. ${ }^{197}$ Less than one week after BT rejected Earthlease's offer, BT received an unsolicited buyout proposal from West LB, a state-

192 See Joint Petition of Global Crossing, Ltd, and Frontier Corp., Case 99-C-0530, N.Y. Pub. Serv. Comm'n, Dec. 1, 1999 (order approving petition).

193 See Oftel, Determination under Condition 83.27 of Schedule 1 to the Public Telecommunications Licence Granted to British Telecommunications PLC Concerning the Entry into Force of the Condition "Requirement to Provide Access Network Facilities," Aug. 8, 2001 (explaining local loop unbundling progress and problems).

194 See Jon Ashworth, Second Approach on BT's Fixed-Line Network, TIMES OF LONDON, Aug. 6, 2001, at 22. In mid 2001, Oftel was considering reducing BT's wholesale rates by more than $70 \%$. Jamie Doward, BT Eyed Network Sell-Off, OBSERVER, Aug. 5, 2001, at 2 (noting that Oftel has invited BT's rival operators to suggest what they believe is a fair price for unbundled loop rentals; proposals range from BT's current charge of $£ 6.17$ per month per line to $£ 1.50$ per month).

195 Doward, supra note 194, at 2.

196 Oftel Meets With Earthlease, EvEnING STANDARD, Aug. 2, 2001, at 38.

197 Simon Goodley, German Move for BT Fixed-Line Arm Network Group has fl2bn in Annual Revenues, DAILY TEL. LONDON, Aug. 6, 2001, at 32. 
owned German investment bank. ${ }^{198}$ West LB offered to buy BT's entire fixed-line infrastructure for $£ 18$ billion, including $£ 5$ billion in cash. ${ }^{199} \mathrm{BT}$ declined.

If BT had accepted Earthlease's bid, BT would have lost its "last mile" of wires connecting its 28 million customers to its local exchanges. One BT executive said "the local loop [is] . . . the core business of BT. And ... you don't outsource your core business." ${ }^{200}$ If BT had divested its local loops, the company would have had to negotiate interoperability standards and an interconnection agreement with Earthlease.

Alternatively, if BT had accepted West LB's offer, BT would have had to buy capacity over its old lines, thus leaving BT as a disintegrated retailer of telecommunications services. The West LB proposal would have been less complex to effectuate because BT could have sold its entire fixed-line network as a single entity, but it nevertheless would have been difficult to value an entire network infrastructure. Industry analysts' estimates of the value of BT's network varied widely, but the average estimate exceeded West LB's price by more than $£ 5$ billion. ${ }^{201}$ BT evidently concluded that unsolicited proposals for divestiture would not adequately compensate the company for the value of infrastructure assets and the costs associated with dismantling its integrated business.

\section{iii. Regulatory Divestiture, or "Velvet Divorce"}

One of us has previously examined the incentives for ILECs voluntarily to undertake structural separation. ${ }^{202}$ Sidak suggested at an American Enterprise Institute conference in August 1997 that the Telecommunications Act of 1996 had been a failure with respect to its local and long-distance entry provisions, and that one scenario that might break the logjam would be a "velvet divorce" of the following form:

[Under this scenario,] the local exchange carriers spin off their operating companies completely and create a separate entity that will hold all unregulated or non-local exchange carrier activities. Those non-local exchange carriers are then able to buy resale and unbundled network

198 Id.

199 Ashworth, supra note 194.

200 Tim Richardson, BT Retail Chief 'Fiercely Opposed' to Sale of Local Loop, THE REG., Aug. 29, 2001, http://www.theregister.co.uk/content/archive/21336.html.

201 Hugo Dixon, Global Finance-Breaking Views, WALL ST. J. EUR., Aug. 8, 2001, at 24 (summarizing industry analysts' average estimate of BT Wholesale's value to be $£ 23$ billion).

202 See SIDAK \& SPULBER, supra note 7, at 551-57; Robert E. Hall, Paul W. MacAvoy \& Robert D. Willig, Panel Discussion, in Is THE TeleCOMMUNICATIONS ACT OF 1996 BROKEN? IF SO, HOW CAN WE FIX IT? 21 (J. Gregory Sidak ed., 1999) (remarks of J. Gregory Sidak, moderator). 
elements on the same pricing terms as AT\&T, MCI, Sprint, and others. Then, those pieces of the former local exchange carriers immediately enter the interLATA market. The local exchange operations remain as some highly regulated activity that cannot . . . engage in other lines of business. ${ }^{203}$

The operative word in this passage is "immediately." As envisioned by Sidak in 1997, this form of regulatory divestiture would entail the immediate lifting of all Section 271 barriers on an RBOC's provision of interLATA service once the RBOC had structurally separated itself. ${ }^{204}$ In practice, of course, voluntary structural separation or divestiture by an RBOC has not been treated in this manner by regulators or competitors.

The divestiture of AirTouch from Pacific Telesis in April 1994 is instructive. $^{205}$ After more than a year of state and federal regulatory reviews, AirTouch became a separately owned and managed company that was publicly traded and that had no local exchange operations. Still, the Department of Justice (acting upon MCI's complaint) continued to regard AirTouch as a "successor" to a Bell operating company, which meant that, under the Modification of Final Judgment, AirTouch could not offer its wireless customers its own interLATA service. It took AirTouch a year of litigation for a federal court to confirm the obvious: A wireless company

203 Id. (emphasis added). The label "velvet divorce" alludes, of course, to the peaceful bifurcation of Czechoslovakia into the Czech Republic and Slovakia after the collapse of communism.

204 Sidak and Spulber elaborated in 1997 on the potential for regulatory divestiture to break the Section 271 logjam:

If an RBOC could shed itself of ownership of its local exchange network, it would have a powerful basis for arguing that it should be free immediately to offer in-region interLATA service, notwithstanding the onerous "checklist" procedure specified in Section 271 of the Communications Act. For an RBOC, rapid entry into the interLATA market would be a major accomplishment, for securing the permission to enter that long-distance market was the principal objective that the RBOCs sought in the 1996 legislation. Following the spinoff transaction, an RBOC would no longer own bottleneck facilities in the local market. As a mere reseller of local exchange services, the post-spinoff RBOC would have no ability to exclude competitors, as regulators have perennially feared. In other words, the RBOC would shed itself of the distinguishing characteristic that provided the rationale both for the imposition of the interLATA restriction in the Modification of Final Judgment and for the subsequent checklist procedure in the 1996 legislation for lifting that restriction. Nonetheless, the RBOC would retain a valuable brand name with which to market lucrative interLATA services within the states in which it formerly provided local exchange services. In short, the RBOC's means of lifting the regulatory quarantine is divestiture.

SIDAK \& SPULBER, supra note 156, at 556. Another motivation for this strategy of voluntary divestiture would be for the ILEC to prevent opportunistic behavior by regulators in the pricing of unbundled network access and in compelling cross subsidies to residential and high-cost customers. See id. at 553, 556.

205 See MACAVOY, supra note 142, at 196-200. 
that is completely divested from an $\mathrm{RBOC}$ is no longer an $\mathrm{RBOC}$ for regulatory purposes. ${ }^{206}$

\section{e. Enhanced Services}

Ignored by Mr. Armstrong and other proponents of mandatory structural separation is the fact that the FCC previously rejected that form of regulatory intervention after trying for many years to make it work. The FCC required that the Bell operating companies ("BOCs") provide "enhanced services" through separate subsidiaries. ${ }^{207}$ That regulatory experiment, however, produced smaller benefits and greater costs than the FCC had expected, and the agency accordingly scrapped structural separation in $1986{ }^{208}$ The FCC first reviewed the costs of structural separation:

Structural separation imposes opportunity costs by discouraging the BOCs from designing innovative enhanced services that utilize the resources of the public switched network. Such innovation losses, resulting from the physical, technical, and organizational constraints imposed by the structural separation requirements, directly harm the public, which does not realize the benefits of new offerings. ${ }^{209}$.

206 United States v. Western Elec. Co., 890 F. Supp. 1 (D.D.C. 1995)

207 The definition of "enhanced" service was always Delphic: it was anything that was not "basic" service. The U.S. Court of Appeals for the Ninth Circuit defined the term this way:

[T] he FCC's terms "basic" and "enhanced" . . . distinguish between regulated common carrier communications services, which consist largely of plain old telephone service (POTS), and unregulated data processing services which use the telephone network to convey information from remote computers to customers' terminals. In the FCC's formal terms, basic service is the offering of a "pure transmission capability over a communications path that is virtually transparent in terms of its interaction with customer supplied information." An enhanced service combines basic service with "computer processing applications [that] ... act on the format, content, code, protocol or similar aspects of the subscriber's transmitted information, or provide the subscriber additional, different or restructured information, or involve subscriber interaction with stored information.

Califomia v. FCC, 905 F.2d 1217, 1223 n.3 (9th Cir. 1990) (internal citations omitted) (quoting Final Decision, Amendment of Section 64.702 of the Commission's Rules and Regulations (Second Computer Inquiry), 77 F.C.C.2d 384, 387, 420 (1980), and citing 47 C.F.R. $\$$ 64.702(a) (1989)).

208 In re Amendment of Sections 64.702 of the Commission's Rules and Regulations (Third Computer Inquiry), and Policy and Rules Concerning Rates for Competitive Common Carrier Services and Facilities Authorizations Thereof, Communications Protocols under Section 64.702 of the Commission's Rules and Regulations, 104 F.C.C.2d 958 (1986) (report and order). The structural separation requirement applied to AT\&T also, but for the ease of exposition we discuss only the BOCs. 209 Id. $\uparrow 89$, at 1007. 
The FCC further observed that

direct costs on the BOCs from the duplication of facilities and personnel, the limitations on joint marketing, and the inability to take advantage of scope economies .... are indications of more fundamental costs of structural separation-namely, that the BOCs are unable to organize their operations in the manner best suited to the markets and customers they serve. $^{210}$

In the FCC's judgment, a lesser, nonstructural remedy could achieve the intended public-interest benefit at a lesser cost to consumer welfare:

These costs, which are potentially very significant, can be eliminated to a large extent if structural separation is replaced with nonstructural safeguards. Even though such safeguards, by their very nature, would place some restrictions on BOC activities, they would largely avoid imposing regulatory limitations on the design and implementation of new services. ${ }^{211}$

Therefore, the FCC concluded, "compared with well-tailored nonstructural safeguards, structural separation restricts effective BOC participation in the markets for [enhanced services] and, accordingly, disserves the public's interest in obtaining the benefits of more price and service competition." 212

The FCC further concluded in 1986 that, in addition to having greater costs than nonstructural safeguards, structural separation did not produce "significantly greater" benefits for consumers than would nonstructural safeguards. ${ }^{23}$ The FCC first made this comparison with respect to possible cross-subsidization. ${ }^{214} \mathrm{Next}$, the Commission considered the argument

210 Id. . 91 , at 1008.

211 Id. ๆ91, at 1008-09.

212 Id. $\{93$, at 1009 . The FCC also found that the waiver process was not an acceptable check on the inefficiencies of structural separation:

We also find the waiver process to be ineffective in addressing the problems we have found with structural separation .... Despite our best efforts to expedite the waiver process, the adversarial nature of such proceedings has delayed their resolution, which has necessarily deferred any societal benefits that the integrated service could offer.

Id. $\uparrow 94$, at 1009-10.

213 Id. 796 , at 1010.

214 Id. ("The availability of bypass and other new technologies places some limits on the BOCs' ability to shift costs from their unregulated services to their regulated offerings without reducing the demand for those offerings. This is evidenced by the increase of competition in intraLATA toll markets and the development of private networks and shared tenant services. The persistent political and regulatory pressures to minimize rural, residential, and small business local 
currently made by AT\&T to justify mandatory structural separation of the ILEC - discriminatory access to network interconnection:

We also conclude that our nonstructural requirements will perform as well as structural separation in combating the possibility of discrimination by the BOCs. We believe that the discrimination potential inherent in the BOCs' control of the local exchange monopolies has eroded since the BOC Separation Order. We do not dispute that the BOCs retain some ability to establish network standards that discriminate against competing enhanced services. However, several factors check the BOCs' use of this power. First, when setting network standards the BOCs must coordinate with one another, other exchange carriers, and interexchange carriers through standards groups .... While the standards adopted by these groups are voluntary, significant departures by the BOCs that affected enhanced service vendors' ability to provide services would be readily apparent to industry participants and the Commission, and would be subject to investigation and appropriate remedies. Second, the growth of bypass and other alternatives to local service, by eroding the local monopolies, will limit the effects of such discrimination to some extent. Third, and most importantly, our CEI [comparably efficient interconnection] and Open Network Architecture requirements are specifically designed to ensure that all enhanced services providers, including the BOCs' unregulated operations, receive equal access to the BOCs' basic facilities, and our information disclosure requirements give enhanced service providers timely technical and marketing information in order to utilize those basic facilities. ${ }^{215}$

Given this assessment of the costs and benefits of structural separation for the BOCs' provision of enhanced services, the FCC abandoned its policy in favor of a less burdensome alternative. The Commission found that "the costs from the structural separation requirements in lost innovation and inefficiency render these requirements far less desirable than nonstructural safeguards."216 The FCC also stressed the importance of preserving economies of scope with respect to a BOC's marketing of enhanced services:

Our elimination of structural separation for . . the BOCs will permit these carriers to engage in the joint marketing of enhanced and basic

exchange rates, even to levels below cost, also limit the BOCs ability to shift costs to regulated services.").

215 Id. 797 , at 1011.

216 Id. I98, at 1011-12. 
services. We do not view such joint marketing as an improper, anticompetitive practice by these carriers and see significant public costs and few benefits in carving out a limited area of structural separation for marketing. Marketing plays an important role, and represents a significant cost, in bringing new services to the public. We see no reason to handicap ... the BOCs competitively in this regard, particularly when significant competitors in the markets for enhanced and integrated systems are not so limited. Again, in our view, the nonstructural safeguards we establish in this Order adequately address the legitimate concerns of some competitors that joint marketing not provide a vehicle for cross-subsidization, discrimination in the provision of basic services, or improper use of customer proprietary information. ${ }^{217}$

These same considerations apply with equal, if not greater, force in 2002 to an ILEC's joint marketing of local telecommunications services to end consumers and unbundled network access to CLECs.

\section{The Probable Cause of CLEC Failures}

The primary reason for CLEC failures has been the building of capacity too rapidly ahead of demand. This phenomenon became known as the Field of Dreams strategy: "If you build it, they will come." Unfortunately for many CLECs, the customers did not come quickly enough. A May 11, 2001 account in the Wall Street Journal provided a sober assessment of the capacity glut:

Hundreds of upstarts rushed to build state-of-the-art networks to carry the expected surge of demand, and incumbents such as AT\&T Corp. and the Baby Bells also awakened to the opportunity, investing billions in their own wireless and Internet businesses. Investors rushed to supply the cash, and Wall Street firms have made $\$ 7$ billion in fees by raising debt and equity for the companies since 1995. But the demand didn't materialize as quickly as expected, and the Baby Bells proved to be tough competitors for the upstarts. Today, more than $97 \%$ of fiber-optic capacity goes unused. ${ }^{218}$

In 2000, capital expenditures by the new local carriers increased $39 \%$, while the revenues generated from the networks added with this capital

217 Id. $\uparrow 99$, at 1012

218 Gregory Zuckerman \& Deborah Soloman, Telecom Debt Debacle Could Lead to Losses of Historic Proportions, WALl ST. J., May 11, 2001, at A1. 
reportedly increased only $11 \% .{ }^{219}$ With so much excess capacity, some CLECs exit the market because the market price falls below their average variable cost. ${ }^{220}$

During the eighteen months spanning May 2000 through March 2002, there were at least twenty-four notable CLEC failures. Table 1 lists the major CLEC failures in reverse chronological order. Other plausible explanations for CLEC failures were an over-reliance on resale and reciprocal compensation arbitrage. In the following Sections, we examine the likely cause of the CLECs' problems. ${ }^{221}$

\section{A. Faulty Business Strategies}

To gauge the initial success of each CLEC, it is more productive to examine how it has translated investment in fixed assets into revenues. The successful firms should be enrolling customers and realizing revenues as they deploy their networks. But CLECs that fail to attract customers as rapidly as they invest capital are obviously more likely to fail to convince investors that they should continue to fund negative cash flows.

Among the better CLECs in translating investment in fixed assets into revenues have been Time Warner, RCN, and Intermedia. Among the least successful have been Rhythms, Covad, NorthPoint, and Teligent. ${ }^{222}$ The latter firms have entered bankruptcy, while the former have survived thus far without recourse to Chapter 11. Even though the more successful firms have suffered a substantial decline in market capitalization, they continue to grow and to invest in facilities. The failing firms simply did not attract customers and generate revenues at a rate that was commensurate with their deployment of capital facilities.

219 Tom Fredrickson, Too Many Lines, Too Few Callers; Telecom Upstarts Shelving Expansion Plans, CRAIN'S N.Y. BUS., Apr. 23, 2001, at 20.

220 For the derivation of the exit rule, see WLllam J. Baumol \& Alan S. BLinder, MICROECONOMICS: PRINCIPLES AND POLICY 156 (7th ed. 1995).

221 This discussion relies extensively on ROBERT W. CRANDALL, AN ASSESSMENT OF THE COMPETITIVE LOCAL EXCHANGE CARRIERS FIVE YEARS AFTER THE PASSAGE OF THE TELECOMMUNICATIONS ACT (report prepared for SBC Communications, June 2001), available at http://www.criterioneconomics.com/documents/Crandall\%20CLEC.pdf.

222 These conclusions are based on a regression of the logarithm of revenues in a given quarter on the logarithm of fixed assets in the previous quarter and separate dummy variables for each CLEC for a sample of thirty-seven publicly traded CLECs. See CRANDALL, supra note 221. 
Table 1. Major CLEC Failures, May 2000-March 2002

\begin{tabular}{|c|c|c|}
\hline Date & Company & Notes \\
\hline $1 / 31 / 02$ & McLeodUSA & Chapter 11 \\
\hline $1 / 28 / 02$ & Global Crossing & Chapter 11 \\
\hline $11 / 16 / 01$ & Net2000 & Chapter 11 \\
\hline $8 / 15 / 01$ & Covad & Chapter 11 \\
\hline $8 / 2 / 01$ & Rhythms & Chapter 11 \\
\hline $6 / 2 / 01$ & PSINet & Chapter 11 \\
\hline $5 / 21 / 01$ & Teligent & Chapter 11 \\
\hline $5 / 14 / 01$ & 2nd Century Communications & To Cease Operations \\
\hline $4 / 18 / 01$ & WinStar & Chapter 11 \\
\hline $4 / 5 / 01$ & Pathnet Communications & Chapter 11 \\
\hline $3 / 30 / 01$ & Advanced Radio Telecom & Chapter 11 \\
\hline $3 / 1 / 01$ & Vitts & Ceased Operations \\
\hline $1 / 17 / 01$ & NorthPoint & Chapter 11 \\
\hline $12 / 30 / 00$ & Jato & Ceased Operations \\
\hline $12 / 27 / 00$ & Digital Broadband Communications & Chapter 11 \\
\hline $12 / 18 / 00$ & Maverix.net & To Cease Operations \\
\hline $11 / 17 / 00$ & Prism Communication Services & Ceased Operations \\
\hline $11 / 14 / 00$ & ICG & Chapter 11 \\
\hline $11 / 7 / 00$ & Picus Communications & Chapter 11 \\
\hline $10 / 31 / 00$ & UBNetworks & Chapter 11 \\
\hline $9 / 28 / 00$ & NETtel & Chapter 11 \\
\hline $8 / 16 / 00$ & Columbia Telecommunications & Chapter 11 \\
\hline $8 / 16 / 00$ & American MetroComm & Chapter 11 \\
\hline $5 / 17 / 00$ & GST & Chapter 11 \\
\hline
\end{tabular}

Source: GST TELECOMMUNICATIONS INC., 1999 SEC FORM 10-K (2000); Noguchi, supra note 6; Overview of Telecom Shakeout, THE DIGEST, Aug. 22, 2001; Cynthia L. Webb, Rhythms to Cut Off Its DSL Subscribers, WASH. POST, Aug. 11, 2001, at E1; Krissah Williams, Tech Slump Short-Circuits Companies' Plans to Build, WASH. POST, Aug. 15, 2001, at T3; Press Release, McLeodUSA Inc., McLeodUSA Reaches Agreement with Bondholder Committee (Jan. 31, 2002); 2nd Century Communications Closes Doors, May 14, 2001, at http://www.CLEC.com (last visited Mar. 15, 2002); Global Crossing, Chapter 11 Sequence of Events, at http:/www.globalcrossing.com/xml/res/ res_events.xml (last visited Apr. 4, 2002); Chuck Holt \& Mark Reddig, Problems Put Fixed-Wireless CLECs in a Poor Light, but Experts Say Future Still Bright, May 1, 2001, at http:/www.CLEC.com (last visited Mar. 15, 2002); Net2000 Files for Chapter 11, Sells to Cavalier, Nov. 16, 2001, at http://www.CLEC.com (last visited Mar. 15, 2002). 
What accounts for this wide differential in the ability of CLECs to generate revenues from their capital investments? An empirical analysis of CLECs that are publicly traded and for which there is information on network deployment, customer base, and business strategy provides at least a tentative conclusion. Those CLECs that rely on building their own networks are able to generate greater revenues per unit of capital investment than those that rely on the leasing of unbundled network elements ("UNEs") from ILECs or on the resale of ILEC services. Having its own facilities allows the entrant to develop services that are attractive to subscribers. $^{223}$

Turning to the customer base, there appears to be little difference in the performance between CLECs that target business customers and those that primarily serve residential customers. Apparently, the few CLECs that address the residential market, such as RCN, do not systematically underperform the vast majority of CLECs that target the business market, all other factors being equal. Nor does reliance upon reciprocal compensation payments, primarily from terminating Internet traffic, contribute significantly to revenue growth - a surprising result given the limited effort required to obtain such revenues when terminating calls directed toward an ISP. ${ }^{224}$ The FCC's decision in April 2001 to revise and reduce reciprocal compensation rates has severely limited the success of this strategy. $^{225}$

A few CLECs have used a resale and UNE strategy with limited success, and Intermedia has been relatively successful with a UNE-only strategy, but empirical analysis suggests that building one's own network is likely to be the best way to build revenues. Of course, this does not guarantee that an entrant will ultimately become profitable and survive. Only time will provide the proof of long-term profitability.

There is simply no support for the notion that the inability to gain interconnection through UNEs or the transfer of resale customers has impeded CLEC growth. Empirical analysis simply leads to the conclusion that building one's own network is likely the best platform strategy for long-term revenue growth. A mixed strategy of using UNEs or resale with one's own network appears to work tolerably well, but simply relying on the ILEC's network appears to be a strategy that limits a CLEC's growth.

223 See id. These conclusions are based on a regression analysis of the logarithm of revenues on lagged fixed capital and dummy variables reflecting network strategy (own facilities, UNEs, resale, or a combination of these choices), dummy variables for concentration on business or residential subscribers, and a dummy variable for reliance on reciprocal compensation.

224 See infra text accompanying note 227.

225 In re Developing a Unified Intercarrier Compensation Regime, 16 F.C.C.R. 9610 (2001) (notice of proposed rulemaking). 
Just changing the nameplate on the service is not typically a very good strategy for attracting customers. The empirical evidence supports Justice Breyer's assessment in $A T \& T$ Corp. v. Iowa Utilities Board: "A totally unbundled world - a world in which competitors share every part of an incumbent's existing system, including, say, billing, advertising, sales staff, and work force (and in which regulators set all unbundling charges)-is a world in which competitors would have little, if anything, to compete about. ${ }^{226}$

\section{B. Unsuccessful CLECs}

As shown in Table 1, a large number of CLECs have filed for bankruptcy protection due to their inability to generate revenues and cash flows that are sufficient to justify their aggressive investment strategies. The most common problems that have plagued these unsuccessful CLECs have been over-expansion (leading to poor quality), reliance on resale, and reliance on reciprocal compensation arbitrage. The last of these problems deserves some elaboration.

Reciprocal compensation connotes the charges that the ILEC pays the CLEC to terminate calls that the ILEC's customers make to subscribers on the CLEC's (typically much smaller) access network. (The CLEC reciprocally owes the same payments to the ILEC when the CLEC originates traffic that terminates on the ILEC's network.) By focusing on customers that would not make outgoing calls to other carriers' networks, but rather would only receive traffic from other carriers, the "recip-comp" CLECs were eligible to receive large amounts of compensation to terminate traffic on their networks at a cost far less than the regulated termination charge. This strategy was, in essence, an arbitrage play, made possible by (1) the reciprocal application to the CLECs of the ILEC's regulated rates for providing higher-cost terminating access and (2) the inherently asymmetric traffic patterns of dial-up Internet Service Providers ("ISPs"), which generate few if any outgoing calls. ${ }^{227}$

226525 U.S. 366, 430 (1999) (Breyer, J., concurring in part and dissenting in part).

227 See generally Global Naps, Inc. v. FCC, 247 F.3d 252 (D.C. Cir. 2001); Worldcom, Inc. v. FCC, 246 F.3d 690 (D.C. Cir. 2001); J. Gregory Sidak \& Daniel F. Spulber, Cyberjam: The Law and Economics of Internet Congestion of the Telephone Network, 21 HARV. J.L. \& PUB. POL'Y 327 (1998). 
1. ICG Communications, Inc.

ICG Communications, Inc. filed for Chapter 11 bankruptcy in September $2000 .{ }^{228}$ When asked to comment on ICG's recent performance, Andrew Morley of Level 3 Communications stated, "[Y]ou need to know who your customers are, know why you serve them and remember they are your No. 1 priority. That's where I think ICG took its eye off the ball.,"229 An equity analyst said that "the company put in all [those] lines and a lot of them must not have been working right" such that "major customers [are] saying they may pull their business." ${ }^{\text {,230 }}$ Thus, industry sources believe that over-expansion was a major problem in the case of ICG, leading to poor product quality, and, eventually, lost business.

These views of ICG's problems are supported by data on its revenue and access-line growth from 1998 to the third quarter of 2000. During this time period, ICG's average revenue growth was approximately $9.1 \%$ per quarter, while average line access lines growth was approximately $19 \%$ per quarter. ICG was extracting less money for each access line in its network over this time period. ${ }^{231}$ The more successful CLECs suffered much smaller declines in revenues per line, and one-Allegianceactually experienced an increase in revenues per line over this period.

\section{CTC Communications}

Another CLEC that relies heavily on resale is CTC Communications. CTC provides local and long-distance telephone, and high-speed data services, ${ }^{232}$ and it leases $97 \%$ of its network lines through resale agreements. CTC has been very aggressive in adding capital assets. In the first quarter of 1998, CTC reported only $\$ 1.7$ million in capital assets, but it expanded steadily to over $\$ 195$ million in assets by the fourth quarter of 2000 . During the period, revenues rose steadily from $\$ 12.8$ million to $\$ 62.3$ million. Thus, capital assets were growing at about $43 \%$ per quarter, while revenues were growing at about $14 \%$ per quarter. Given the difference in the growth rate of assets over revenues, CTC has since revised its business model, adding new lines only after it has signed on

228 Jeff Smith, ICG Communications Files for Bankruptcy, DENV. RoCKy MOUNTAN NEWS, Nov. 15,2000 , at $1 \mathrm{~B}$.

229 Id.

230 Heather Draper, ICG's Tumble a Wake-up Call to Telecom Firms, DENV. ROCKY MOUNTAIN NEWS, Sep. 24, 2000, at 1 G (quoting Dave Heger of A.G. Edwards).

231 Revenue figures are obtained from various SEC Form 10-Qs.

232 CTC COMMUNICATIONS CORP., 1999 SEC FORM 10-K, at l (June 29, 2000). 
new customers. ${ }^{233}$ The revised plan was announced at a time when CTC's stock price had fallen from a high of over $\$ 50$ to around $\$ 5$.

Over-expansion is clearly a major source of CTC's problems and this is obviously one reason for its new deployment strategy, but another problem is its reliance on resale. A simple resale strategy has caused serious problems for many CLECs, most notably AT\&T. If AT\&T found resale unprofitable, then there is no reason to think that a smaller firm, such as CTC, would be able to build a sustainable business by reselling ILEC services.

\section{Teligent}

On May 21, 2001, Teligent filed for Chapter 11 bankruptcy protection. Trading of the firm's stock was halted on NASDAQ at fifty-six cents per share. Fourteen months before the bankruptcy filing, Teligent's stock was trading at nearly $\$ 100$ per share and the firm was seen as potentially one of the most powerful CLECs in the industry. ${ }^{234}$

The reason for Teligent's failure was over-expansion, but of a type different from most other CLECs. Teligent's business model was to provide voice and data services over a fixed-wireless system. This strategy avoids the last-mile access problem, but it can be very costly. ${ }^{235}$

Teligent ran into problems when it tried to build networks in large numbers of new markets all at once and relied too heavily on debt financing for the necessary capital expenditures. Many of Teligent's new markets might have eventually been very profitable because it would have offered a service far different from that of the ILECs, but its poor debt management resulted in a financial squeeze and subsequent bankruptcy. The lessons to be taken from Teligent's failure are that building local networks takes time and that markets must be added at reasonable rates so that profits from existing markets can ease the cost of adding new markets and thereby avoid a drain of capital reserves.

\section{NorthPoint Communications}

Before declaring bankruptcy and then selling its network assets to AT\&T in March 2001, NorthPoint Communications was one of the largest

233 Tom Fredrickson, Too Many Lines, Too Few Callers; Telecom Upstarts Shelving Expansion Plans, CraIN'S N.Y. BUS., Apr. 23, 2001, at 20.

234 Yuki Noguchi, Teligent Files for Chapter 11 Protection; Move Adds to Doubt On Broadband's Role, WASH. POST, May 22, 2001, at El.

235 Id. 
digital subscriber line ("DSL") providers in the nation, with approximately 100,000 customers. NorthPoint's business model was to be a wholesale supplier of DSL, using ILEC UNEs and selling the service to ISPs, which in turn enrolled the end users. ${ }^{236}$ This business model may have made sense to the extent that NorthPoint could have captured a better margin by being the initial producer of the service while avoiding the costs of retailing. Unfortunately, the bursting of the Internet bubble in the stock market created financial problems for many of NorthPoint's clients, such as Telocity. As a result, NorthPoint had to revise downward its third quarter reported revenue from $\$ 30$ million to $\$ 24$ million because about $30 \%$ of NorthPoint's clients where delinquent in paying their bills. ${ }^{237}$

After the revised earnings statement, Verizon (one of the four largest ILECs in the United States) promptly cancelled a deal to purchase NorthPoint due the company's financial disarray. ${ }^{238}$ By the time that the Verizon deal had fallen through, the capital markets had sharply reduced the flow of funds to the failing Internet firms. NorthPoint was consequently left with a partially completed network and a huge shortfall of capital funding because it had not pursued additional financing, counting instead on the Verizon deal to be completed. ${ }^{239}$ NorthPoint was forced to file for bankruptcy protection, and, eventually, to sell its network elements to AT\&T.

Interestingly enough, in the AT\&T deal with NorthPoint, AT\&T required NorthPoint to suspend operations, ensuring that it would not have to honor contracts with NorthPoint's ISP clients. AT\&T stated that it preferred to offer the entire service itself, rather than acting as a wholesale agent for DSL service. ${ }^{240}$

\section{Focal Communications}

In 1997, Focal Communications derived over $80 \%$ of its total revenues from reciprocal compensation. With uncertainty looming over a possible FCC decision to reduce reciprocal compensation, Focal was forced to reduce its dependence on reciprocal compensation to $30 \%$ of revenues in the year 2000 and hoped to reduce this figure to $15 \%$ of revenues in 2001 . These efforts were not sufficient to keep its stock price

236 Elizabeth Douglas, 100,000 Subscribers of NorthPoint DSL Face Disconnection, L.A. TIMES, Mar. 28, 2001 , at C3.

237 Peter S. Goodman, Verizon Terminates Deal to Buy Stake in NorthPoint, WASH. PosT, Nov. 30, 2000, at E9.

$238 \cdot$ Id.

239 Douglas, supra note 236, at C3.

240 Id. 
from declining by $80 \%$ in the first half of 2000 as the financial markets reflected a continuing concern over cash flow problems stemming from reliance on reciprocal compensation. ${ }^{241}$ Focal's stock made a 35:1 reverse stock split on March 11,2002, and its adjusted value has fallen by over $99.8 \%$ in the two years since its high of $\$ 77.75$ in March $2000 .^{242}$

Other companies have recognized the folly of building a business strategy on the arbitrage opportunities presented by reciprocal compensation. For example, Intermedia Communications was forced to reduce its expectations of revenue in 2000 as a result of expected reductions in reciprocal compensation fees. ${ }^{243}$ The expected change in fees came as a result of state court rulings recommending the reduction of reciprocal compensation rates. This reduction in expected revenues from reciprocal compensation was cited as one reason why Broadwing abandoned its negotiations to buy Intermedia. As a result, the value of Intermedia's shares fell $14 \%$ in one day. ${ }^{244}$

An even bigger problem from relying on reciprocal compensation is the indirect loss of revenues from poor network design in executing that strategy. Because Focal initially designed its network around extracting reciprocal compensation revenues, $100 \%$ of its access lines were UNE lines. Focal's CLEC competitors were adding their own components and building their own lines while Focal continued to lease UNEs from the ILECs. This was a poor business strategy because it limited Focal's ability to offer product quality that differs from that provided by the ILECs. In the long term, customers are more likely to prefer a CLEC to an ILEC if the CLEC can offer better service, lower cost, or a combination of the two. Focal is unable to offer service or cost improvements over the ILECs because Focal's entire network is based on UNEs.

\section{The Effect on Local Competition of Elimination of Unbundling Requirements}

To meet the goal of the Telecommunications Act of 1996-the development of facilities-based competition in local telephony-CLECs must invest in their own facilities. But every CLEC will forgo facilitiesbased investments so long as it has other opportunities that have higher net present values ("NPV"). Artificially low UNE prices induce CLECs

241 Sandra Jones, A Disconnect for Phone Upstart; Focal Sees Threat to Key Sales Engine, CRAIN's CHI. BuS., Jan. 8, 2001, at 1.

242 Focal Communications, at http://www.focal.com (last visited Mar. 17, 2002).

243 INTERMEDIA COMMUNICATIONS INC., 1999 SEC FORM 10-Q, at 14 (Nov. 14, 2000).

244 Kris Hundley, Intermedia Revenues Come Up Short, ST. PETERSBURG TIMES, July 12, 2000 , at E1. 
continually to defer facilities-based investments because the NPV calculations of UNE leasing are often higher than the NPV calculations of sinking capital into on-net assets. Because the NPV calculus is driven by presently unknown factors-such as the future expected cash flow of the asset-choosing to make an investment today is inherently risky. Moreover, making an investment in telecommunications assets is particularly risky given the industry's technological dynamism and uncertain market demand. The decision to invest commits the CLEC to a particular technology that may reveal itself later to be inferior, and the telecommunications industry has historically been driven by rapidly leapfrogging technologies. ${ }^{245}$ Indeed, new empirical evidence suggests that underpriced UNEs deter CLEC facilities-based investment. James Eisner and Dale Lehman find in a regression analysis of CLEC investment levels across the United States that there is a significant positive relationship between CLEC facilities-based investment and the UNE rates. ${ }^{246}$

\section{Assessment of the CLEC Sector}

We have reviewed the evidence that CLECs that deliberately built out their own networks, having carefully analyzed competition and consumer demand before entry, were able to increase revenues and continue to attract capital. Several of the more successful CLECs combined resale and the leasing of unbundled network elements with the construction of their own networks, but none of these firms relies exclusively on UNEs or resale and these firms added more facilities-based elements over time to improve upon the product that the ILECs offer. The fact that some firms, such as Allegiance, were able to employ a resale and/or UNE strategy as part of their business plan provides strong refutation that the ILECs were responsible for the recent spate of CLEC failures.

Since December 1999, the CLEC share of the nation's access lines has expanded rapidly. By June 2001, the CLECs had $9.0 \%$ of the country's

245 The FCC has noted the unpredictability of technological changes in the communications industry as well. See Implementation of the Local Competition Provisions in the Telecommunications Act of 1996, Intercarrier Compensation for ISP-Bound Traffic, 16 F.C.C.R. 9151 ๆ 51 (2001) (order on remand and report and order) ("Although we cannot anticipate the direction that new technology will take us, we do expect the dramatic pace of change to continue. Congress clearly did not expect the dynamic, digital broadband driven telecommunications marketplace to be hindered by rules premised on legacy networks and technological assumptions that are no longer valid. Section 251(i), together with Section 201, equips the Commission with the tools to ensure that the regulatory environment keeps pace with innovation.").

246 JAMES EISNER \& DALE E. LEHMAN, REgulatoRy BEHAVIOR AND COMPETITIVE ENTRY I, (June 28, 2001) (presented at the 14th Annual Western Conference Center for Research in Regulated Industries) ("We find states with low UNE prices have less facilities-based entry, with more ambiguous effects on the other two forms of entry."). 
switched-access lines and were continuing to grow. ${ }^{247}$ Unfortunately, many of the entrants were not able to survive the large decline in the market for high-technology equity shares that began in March 2000. These companies generally had faulty business plans that were exposed when a declining stock market severely reduced their ability to raise capital. The ensuing shakeout of entrants has been described as "only natural" by the chairman and CEO of Allegiance, who pointed out that the exuberant capital markets of 1999 and early 2000 created an environment in which "no business plan [was] too weak or management team too inexperienced to get funded."

Virtually every exercise in deregulation or market liberalization leads to a wave of entry followed by a wave of bankruptcies. This was the experience in trucking and airline deregulation-two industries in which technology has been rather stagnant. Given the rapid changes in technology in telecommunications and the fact that there are few historical models of competition in local telephone service, the likelihood of failed entry is surely much greater in this market. Nevertheless, the good news is that some entrants are succeeding and growing and that local markets are steadily becoming more competitive.

\section{The Ulterior Motivation for Advocating Mandatory Structural Separation: Raising Rivals' Costs}

We have argued that mandatory structural separation would not produce any benefit to consumer welfare, or any other public interest benefit that we can identify. On the contrary, such regulatory intervention would be a costly non-solution to a non-problem. That conclusion, of course, does not say anything about whether mandatory structural separation would produce private economic benefits to CLECS. That the chairman of AT\&T would so vigorously advocate this new form of regulatory intervention in 2001 suggests that his company would derive considerable strategic advantage from it. In the following sections, we therefore speculate on the nature of the strategic benefit that AT\&T and other CLECs could expect to derive from mandatory structural separation, irrespective of its harm to consumers and the public interest. Such an analysis can clarify for legislators, regulators, and courts the political economy of this proposed intervention.

247 See LOCAL TELEPHONE COMPETITION UPDATE, supra note 2.

248 CLEC Representatives Have Doubts About FCC's 'Recip Comp' Order, TR DAIL., May 15, 2001 (quoting Royce Holland). 
From the perspective of a major CLEC like AT\&T, mandatory structural separation effectuates a strategy of "raising rivals" costs"249 by increasing the incumbent burdens borne by the ILEC. An incumbent burden arises when "incumbents face costs owing to regulation that are not imposed on entrants." ${ }^{250}$ As one of us has previously written with Professor Daniel F. Spulber, "incumbent burdens are analogous to the phenomenon of 'raising rivals' costs,' except that in an industry subject to public utility regulation the 'rival' whose cost is being raised is the incumbent public utility rather than the entrant." ${ }^{, 251}$ In a regulated network industry, "the raising of a rival's cost is a method not of facilitating inefficient exclusion from a market, but of facilitating inefficient entry into it." ${ }^{252}$ Mandatory structural separation of the ILECs would be a newly imposed incumbent burden because, by regulatory fiat, it would compel the incumbent - and only the incumbent-to operate through structurally separate wholesale and retail operations.

If antitrust is predicated on consumer welfare maximization and if telecommunications regulation should share that same orientation, then why does raising a rival's cost matter? Concern over such conduct would seem, at first blush, to focus on competitor welfare rather than consumer welfare. The answer is that the higher costs of rivals are passed along ultimately in higher prices to consumers and reduced levels of output. Moreover, by reducing the productive efficiency of rivals, this strategic behavior erodes profitability and, hence, reduces returns to investors, thus discouraging investment. It also reduces the ability of the rival firm to fund its own investment through retained earnings, because the pool of earnings diminishes by the amount of the inefficiency by which the rival has been handicapped. Consumer welfare, and economic welfare generally, therefore fall as the result of a strategy of raising rivals' costs.

This strategic and anticompetitive implication of mandatory structural separation is sophisticated and subtle because it exploits two other preexisting regulatory policies that concern pricing and cost recovery by the ILECs. First, mandatory structural separation has important implications for the prevailing test that regulators use to define a retail price squeeze, a test that can have the effect of facilitating (inefficient) entry by raising the ILEC's retail price. Because mandatory structural

249 See Thomas G. Krattenmaker \& Steven C. Salop, Anticompetitive Exclusion: Raising Rivals ' Costs to Achieve Power over Price, 96 YALE L.J. 209 (1986).

250 SIDAK \& SPULBER, supra note 156, at 30 . The concept of incumbent burdens originated in Paul W. MacAvoy, Daniel F. Spulber \& Bruce E. Stangle, Is Competitive Entry Free? Bypass and Partial Deregulation in Natural Gas Markets, 6 YALE J. ON REG. 209, 210 (1989).

251 SIDAK \& SPULBER, supra note 156, at 30-31 (footnote omitted).

252 Id. at 31. 
separation raises the ILEC's costs, it evidently would justify a state PUC's ordering a higher retail price floor for the ILEC's retail service. Although plainly harmful to consumer welfare, that strategy of raising rivals' costs facilitates AT\&T's entry into the local market. Second, this strategy becomes even more surreptitious because of the way that state and federal regulators allow, through the process of "jurisdictional separations," an ILEC to recover through its regulated rates the non-traffic-sensitive costs of its network that are incurred in common across both intrastate and interstate services. Because of the reluctance of state regulators to raise the ILEC's allowed price for an unbundled loop and the reluctance of the FCC to raise the ILEC's allowed price for interstate access (which is already subject to a price-cap that declines over time), the additional costs imposed on an ILEC by virtue of mandatory structural separation might, for political rather than economic reasons, be unrecoverable in both the state and federal jurisdictions.

\section{A. Mandatory Structural Separation and the Retail Price-Squeeze Rule}

After the passage of the Telecommunications Act of 1996, AT\&T argued that resale of the ILEC's local service was an essential precursor to, not a substitute for, facilities-based entry under the new legislative scheme. ${ }^{253}$ Section 252(d)(3) of the Communications Act, added in 1996, provides that the discount to which the CLEC is entitled when purchasing the ILEC's wholesale service is based on decremental cost-the cost that the ILEC actually avoids when no longer retailing local exchange service to an end consumer. ${ }^{254}$ As indicated by Mr. Armstrong's remarks discussed earlier in Part $\mathrm{I}^{255}$ AT\&T regarded the avoided-cost discounts set by regulators as too low to make resale a feasible strategy-which is simply to say that AT\&T evidently concluded after 1996 that its own incremental cost of retailing an ILEC's wholesale local service exceeded the ILEC's decremental cost of not retailing that same service. There is, of course, nothing anticompetitive about one set of firms having inherently lower costs than another set of firms when performing a particular productive activity; certainly, such asymmetry of costs should surprise no

253 See John D. Zeglis, Out of the Courts and into the Market: Wouldn't It Be Great?, in Is THE TELECOMMUNICATIONS ACT OF 1996 BROKEN? IF SO, HOW CAN WE FIX IT? 100, 100-01 (J. Gregory Sidak ed., 1999) ("Total service resale offered a chance for easy market entry, followed by more meaningful forms of competition.") (edited text of speech by president of AT\&T delivered Dec. 18, 1997); see also KAHN, LETTING Go, supra note 90, at 47-53, 90-96; Sidak \& Spulber, The Tragedy of the Telecommons, supra note 90.

25447 U.S.C. $\$ 252$ (d)(3) (2000). For the statutory text, see supra note 169.

255 See supra text accompanying note 60. 
one in an industry in which the government has heavily regulated one set of firms and thus inevitably skewed its choice of production technology.

Rather than pursue a local competition strategy predicated on resale (or on widespread leasing of unbundled loops at regulated prices), AT\&T pursued a costly facilities-based strategy of entry into the local telecommunications market, as noted in Part $\Pi{ }^{256}$ AT\&T spent more than $\$ 100$ billion between 1996 and 2001 to buy TCI and MediaOne, two of the nation's largest cable MSOs. AT\&T thereby gambled that, through substantial subsequent investment, the company could upgrade and combine the (generally one-way) cable systems of the various MSOs to create a viable two-way network for local telecommunications. For AT\&T's facilities-based strategy to succeed, the company must be able to offer consumers a lower (quality-adjusted) retail price for local telecommunications services than the ILEC's retail price, or new service, or both. By December 2001, however, the New York Times concluded that " $[t]$ he rough financial calculations suggest that the cable strategy was a wash or a modest loser for the company's shareholders ...."257

State PUCs faced a similar issue even before their implementation of the local interconnection provisions of the Telecommunications Act of 1996. When entrants have sought to compete in local telecommunications markets (such as intraLATA toll service) by purchasing the use of the ILEC's bottleneck elements, state PUCs have regulated not only the ILEC's maximum price of the bottleneck elements sold to CLECs, but also the ILEC's minimum price of the retail service sold to consumers in competition with the CLEC's retail service. The purpose of the two levels of price regulation is to prevent a price squeeze on the CLEC's sale of the retail service. If this retail profit margin is too small, a retail price squeeze is said to have occurred. The California Public Utilities Commission ("CPUC"), one of the earliest state PUCs to adopt a precise price-squeeze test after hearing extensive economic testimony, announced its rule in 1993 in Alternative Regulatory Frameworks for Local Exchange Carriers. ${ }^{258}$ Using the concept of long-run incremental cost ("LRIC"), the

256 In fact, AT\&T's decision to acquire cable MSOs represented a reversal of its strategy for entry into local telecommunications. As late as December 1997, the president of AT\&T publicly said, "Although unbundled network elements are the only practical route for broadly delivering benefits of competition to residential and most business customers within the next few years, over time AT\&T and other long-distance carries will undoubtedly build some local network facilities of their own." Zeglis, supra note 253 , at 102 . AT\&T ultimately declined to build its own local network facilities or to lease unbundled loops on a large scale.

257 Seth Schiesel, The AT\&T Chief's Report Card: Did Armstrong Do as Well as Could Be Expected?, N.Y. TIMES, Dec. 22, 2001, at C1, C2.

258 In re Alternative Regulatory Frameworks for Local Exchange Carriers, and Related Matters (Part 2 of 4), Decision No. 93-09-076, Cal. Pub. Utils. Comm'n, Sept. 17, 1993, 1993 Cal. PUC LEXIS 649. 
CPUC said, "A price squeeze may be avoided by requiring that the price floor for the LECs' toll and other competitive services offered under tariff or by contract should not be lower than the sum of the tariffed rates for the bottleneck building blocks and the cost (LRIC) of non-bottleneck components. ${ }^{1,259}$ In the case of resale of the ILEC's local service, the LRIC of non-bottleneck components is simply the ILEC's long-run avoided (decremental) cost of retailing.

Price-squeeze regulation, however, can be imprecise and can deter more than simply anticompetitive behavior by the ILEC. The pricesqueeze rule is subject not only to regulatory error, but also to strategic manipulation by competitors. The CLEC's regulatory strategy, obviously, is to importune the state PUC to set for the ILEC the lowest possible price ceiling on UNEs and the highest possible price floor on retail services. In other words, the CLEC's strategic objective is to secure from the regulator a price-squeeze rule that maximizes the likelihood of "false positives"that is, the rule finds an ILEC's slim profit margin on retail services to be anticompetitive when it is not. This strategy also would urge the state PUC to impute the highest possible cost to the ILEC's supply of the nonbottleneck inputs. The result is a profit margin for CLECs that is guaranteed by regulation-and quite possibly guaranteed to exceed the competitive profit margin, given the ILEC's probably greater efficiency in supplying the non-bottleneck retailing functions required to sell local telecommunications service to end consumers. It is, of course, exceedingly

259 Id. *162 (Finding of Fact No. 228). The two largest ILECs in California were then Pacific Bell and GTEC. The firms seeking to provide competitive services (such as local toll service) were, among others, AT\&T and MCI. To "prevent any price squeeze" by Pacific Bell or GTEC, the CPUC reaffirmed an earlier order requiring that "the price floor for the LECs" toll and other competitive services shall not be lower than 'the sum of the tariffed rates for the bottleneck building blocks and the cost (LRIC) of non-bottleneck components." Id. at *42 (quoting In re Altemative Regulatory Frameworks for Local Exchange Carriers, etc., (Part 2 of 2), Decision No. 89-10-031, Cal. Pub. Utils. Comm'n, Oct. 12, 1989, 1989 Cal. PUC LEXIS 576, at *123 (Conclusion of Law No. 7)).

The CPUC's approach to defining and prohibiting price squeezes is representative of the approach used by other state PUCs. See, e.g., In the Matter, on the Commission's Own Motion, to Determine the Total Service Long Run Incremental Costs and Imputation Requirements Under the Michigan Telecommunications Act, Case No. U-11103, Mich. Pub. Serv. Comm'n, Dec. 12, 1996, 1996 Mich. PSC LEXIS 294, at *41 ("In giving effect to this policy [of preventing price squeezes], Subsection 362(2) [of the Michigan Telecommunications Act] expressly states that the rate for a telecommunication service must exceed the sum of the tariffed rates for access and other noncompetitive components used to provide the service and the TSLRIC [total service LRIC] of all other components that are not offered as tariffed services."); In re the Application of Electric Lightwave, Inc. for a Certificate of Authority to Provide Telecommunications Services in Oregon, (CP 1), etc., Order No. 96-021, Or. Pub. Utils. Comm'n, Jan. 12, 1996, 1996 Ore. PUC LEXIS 7, ("[Oregon Revised Statute §] 759.050(5)(b) is designed to prevent price squeezes by establishing an imputation price floor for services sold by telecommunications utilities within competitive zones. It requires that the price for a service offered by a telecommunications utility may not be less than the TSLRIC of nonessential functions plus the price of the essential functions necessary to provide the service."). 
doubtful that consumers could benefit even in the long run from such infant-industry regulation.

How does this potential for strategic abuse of price-squeeze regulation relate to AT\&T's advocacy of mandatory structural separation of ILECs? As noted above, AT\&T has complained since the late-1990s that the wholesale discounts that result from the avoided-cost formula specified by Congress in Section 252(d)(3) of the Communications Act are insufficient to allow AT\&T's profitable entry into local exchange service. Thus, AT\&T has chosen to enter the local access market instead through its costly acquisition of TCI and MediaOne. This strategy is noteworthy because resale and the leasing of unbundled network elements do not even appear to be the preferred mode of CLEC entry. The practical benefit to AT\&T of mandatory structural separation is to increase the ILEC's incremental cost of retailing as a non-bottleneck component within the traditional price-squeeze formula. (The next step in that process, if permitted on antitrust grounds, will be AT\&T's acquisition by Comcast, another cable $\mathrm{MSO}^{260}$ ) In numerous markets, AT\&T is no longer interested in purchasing that non-bottleneck component from the ILEC, as the company has committed itself instead to facilities-based entry through the upgrading of cable television systems. Nonetheless, AT\&T benefits if, under the traditional price-squeeze test, the regulator increases the ILEC's price floor by the amount that mandatory structural separation increases the ILEC's cost of supplying bottleneck inputs and non-bottleneck inputs to its own retailing arm and to the CLECs. (It is not necessary to assume, unrealistically, that the PUC would follow mandatory structural separation with a large increase in rates for local telephone service.)

An additional complexity arises here. If there are economies of scope across the ILEC's wholesale and retail operations, then mandatory structural separation will create increased costs for the ILEC that are jointly attributable to wholesaling and retailing, but not directly attributable to either function on its own. Thus, any allocation of common costs between the two functions will be inherently arbitrary on economic grounds. On political grounds, however, it may be much harder for regulators to justify attributing a share of the increased common costs to the LRIC of the bottleneck elements, such as unbundled loops, for such an allocation of common costs would tend to discourage non-facilities-based entry into local telecommunications through the leasing of UNEs. (In comparison, in 1996, the FCC expressly refused to use Ramsey-pricing reasoning to allocate to unbundled loops any appreciable share of the

260 Steve Lohr, AT\&T's Cable Deal: News Analysis; Clash of the Convergers, N.Y. TIMES, Dec. 20, 2001, at Cl. 
ILEC's forward-looking common costs, on the rationale that loops were the least substitutable of all of the ILEC's unbundled network elements. ${ }^{261}$ ) Therefore, state PUCs will have an incentive to attribute all or most of the increased common costs of mandatory structural separation to the ILEC's retailing functions, while keeping the regulated prices of UNEs at their current levels. The state PUCs also will have a pronounced political incentive to characterize the increased common costs as properly recoverable through FCC-regulated rates for interstate services rather than through PUC-regulated rates for intrastate service-an important institutional consideration to which we now turn.

\section{B. Strategic Exploitation of Jurisdictional Separation of Common Costs}

The ILECs face overlapping regulatory jurisdictions. An ILEC provides intrastate services that are regulated by the state PUC and interstate services that are regulated by the FCC. For example, the FCC regulates the ILEC's price of supplying originating or terminating access for a long-distance call crossing LATA boundaries (usually including state lines), whereas the state PUC regulates the ILEC's price of the same access for intrastate toll calls that do not cross LATA boundaries. The setting of interstate and intrastate prices for access requires that state and federal regulators allocate to each jurisdiction the ILEC's costs of supplying access. The ILEC, however, incurs some costs in common when supplying both the intrastate and interstate services. For example, the cost of installing and maintaining the copper loop leading from the central office switch to the customer's premise is a cost that is common to access services subject to both jurisdictions.

Mandatory structural separation has implications for the ILEC's jurisdictionally common network costs. We explained in Part II that mandatory structural separation would likely raise an ILEC's costs. If, as seems inescapable, any of those cost increases were incurred in common across jurisdictionally separate services, a state PUC's order of mandatory structural separation necessarily would increase the costs to an interstate service that is subject to the FCC's jurisdiction. That increase in the amount of the ILEC's costs of providing interstate service would, all other

261 Local Competition First Report and Order, supra note 96, \696, at 15,853 ("We conclude that such an allocation could unreasonably limit the extent of entry into local exchange markets by allocating more costs to, and thus raising the prices of, the most critical bottleneck inputs, the demand for which tends to be relatively inelastic. Such an allocation of these costs would undermine the procompetitive objectives of the 1996 Act."). Commenting on this reasoning by the FCC, one of us has written with Professor Daniel Spulber that "[i]t is a sham for the FCC to have told incumbent LECs that they can recover their forward-looking common costs only by raising the prices of their most pricesensitive network elements above TELRIC." SIDAK \& SPULBER, supra note 7, at 341. 
things being equal, place pressure on the FCC to allow a higher rate for the regulated interstate service. For political reasons, however, the FCC might resist allowing such a rate increase. ${ }^{262}$ Consequently, a state's decision to order mandatory structural separation would surely affect the interstate jurisdiction and thus implicate the FCC's rate-setting prerogatives.

The FCC and the states address the jurisdictional division of common costs through the "separations" process, codified in Part 36 of the FCC's rules. ${ }^{263}$ That process was a decision jointly made by the states and the federal government to advance shared political goals concerning the structure of rates. It was a modification in each state of the regulatory relationship (which one of us has previously described in contractual terms $^{264}$ ) to which that state was, historically, already a party. The practical effect of the jurisdictional separation of the ILEC's common costs was to interpose the federal government (represented by the FCC) as an additional party to the preexisting regulatory relationship (or contract) between the state and the ILEC. The allocation by state and federal regulators of a substantial share of the ILEC's common costs to the interstate side of its books necessarily carried with it several implied, if not explicit, representations: The FCC would afford the ILEC the reasonable opportunity to recover, through its sale of interstate services at regulated rates, the entire portion of common costs that had arbitrarily been designated as "interstate" in character; the states would correspondingly allow the ILEC the reasonable opportunity to recover, through its sale of intrastate services at regulated rates, the entire portion of common costs that had arbitrarily been designated as "intrastate" in character; and the states and the FCC jointly would ensure that the separations process would enable the ILEC to recover the full amount of common costs. In short, the sum of the parts may not be less than the whole.

The experience of implementing the Telecommunications Act of 1996 raised considerable doubt as to whether the state PUCs and the FCC were credibly committed to granting the ILECs the reasonable opportunity to recover their full common costs of local interconnection. Under Chairman Reed Hundt, the FCC rebuffed, in the First Report and Order on interconnection, ${ }^{265}$ arguments by the ILECs that the FCC's pricing proposals would deny an ILEC the reasonable opportunity to recover its

262 For a discussion of the political resistance of regulators to increase rates to cover costs, see CRANDALl \& WAVERMAN, supra note 165, at 166.

26347 C.F.R. pt. 36. The separations process today removes the ILEC's costs of unregulated services through Part 64, 47 C.F.R. pt. 64 . Interconnection costs and prices are regulated and thus are subject to the Part 36 process of separating the ILEC's regulated costs.

264 See SIDAK \& SPULBER, supra note 7, at 101-77.

265 Local Competition First Report and Order, supra note 96, ๆๆ 696-98, at 15,853-54. 
total costs of providing unbundled network elements and resale. Again, in its Access Reform Order in May 1997, the FCC reaffirmed its desire for the ILECs to price unbundled access to their networks at TELRIC and stated that the agency would address cost recovery issues in a subsequent order, which never appeared during the remainder of Chairman Hundt's tenure or during his successor's. ${ }^{266}$ In August 1997, Chairman Hundt said, "The existing competition efforts in local markets are tiny fish that will not survive in the presence of the incumbent, formerly government-protected, monopolistic, whale-sized local telephone operating companies, not unless state and national governments write and enforce procompetitive rules."267 In short, the FCC's action and inaction over nearly a five-year period from August 1996 to early 2001 suggested that the agency consciously sought to stimulate competitive entry into local telephony by encouraging (or commanding, if the courts would permit) the state PUCs to set UNE prices and resale discounts that would not fully compensate the ILECs for their forward-looking common costs of local interconnection. ${ }^{268}$ Scholars criticized the FCC for engaging in a sophisticated, opportunistic strategy of managed competition. ${ }^{269}$ Chairman Hundt's subsequent memoirs do more to substantiate the basis for that criticism than refute it. ${ }^{270}$

The jurisdictional separations process enables regulators-at the behest of tiny fish as well as large ones like AT\&T and WorldCom-to

266 In re Access Charge Reform, Price Cap Performance Review for Local Exchange Carriers; Transport Rate Structure and Pricing, End User Common Line Charges, 12 F.C.C.R. 15,982 14 (1997) (First Report and Order).

267 Reed E. Hundt, The Light at the End of the Tunnel v. the Fog: Deregulation v. the Legal Culture, in IS THE TELECOMMUNICATIONS ACT OF 1996 BROKEN? IF SO, HOW CAN WE FIX IT? 1, 6 (J. Gregory Sidak ed., 1999) (edited text of speech delivered Aug. 14, 1997).

268 In addition, the FCC appeared to (1) delay the imposition of any alternative mechanism for cost recovery that might engender political controversy and publicly expose the magnitude of the shortfall in cost recovery owing to the pricing rule urged upon the states by the FCC, and (2) maintain that, in the meantime, any claim by an ILEC that the FCC had committed a taking of property was unripe for adjudication, either because cost recovery issues would still (someday) be addressed by the FCC or because no confiscation of an ILEC's property could occur until the ILEC had lost appreciable market share (if not simply profit) to the CLECs.

269 See KAHN, LETTING Go, supra note 253; SIDAK \& SPULBER, supra note 156, at 307-92, 403-26; see also ALFRED E. KAHN, WHOM THE GODS WOULD DESTROY, OR HOW NOT TO DEREGULATE

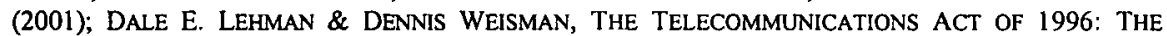
"COSTS" OF MANAGED COMPETITION (2000) (discussing regulatory opportunism in the pricing of UNEs by state PUCs having price-cap regulation for their ILECs); Hausman, supra note 90.

270 REED E. HUNDT, YOU SAY YOU WANT A REVOLUTION: A STUdy OF INFORMATION AGE Politics 154 (2000) ("The conference committee compromises [for the Telecommunications Act of 1996] had produced a mountain of ambiguity that was generally tilted toward the local phone companies' advantage. But under principles of statutory construction, we had broad discretion in writing the implementing regulations. Indeed like the modern engineers trying to straighten the Leaning Tower of Pisa, we could aspire to provide the new entrants to the local telephone markets a fairer chance to compete than they might find in any explicit provision of the law."); see also Glen O. Robinson, Reed Hundt, Revolutionary Manqué, 4 GREEN BAG 2D 197 (2001) (critical review of HUNDT, supra). 
make even more opaque this strategy of managed competition as it concerns the recovery of an ILEC's common costs of interconnection. The FCC has said of the separations process: "While a competitive LEC is free to recover costs according to market demand, an ILEC subject to our jurisdictional separations rules may only attempt to recover costs classified as interstate through charges for interstate services, and costs classified as intrastate through charges for intrastate services." ${ }^{271}$ That statement is incomplete because it ignores the third condition implicit in the jurisdictional separation of an ILEC's common costs: That allowed charges for interstate services and for intrastate services together shall allow the ILEC the reasonable opportunity, in light of observed conditions of market demand, to recover all of the ILEC's common costs. The obligation of state and federal regulators to permit the ILEC to charge rates (and earn revenues, given demand conditions) that fully recover common costs cannot be discharged simply by dividing those common costs into two categories labeled "interstate" and "intrastate." Without the implicit third condition of full recovery of common costs under jurisdictional separation, that intergovernmental process would tempt each regulator to assert that the other was solely responsible for raising allowed rates in its own jurisdiction to permit the recovery of the ILEC's common costs of network interconnection. ${ }^{272}$

If it were not constrained-by the arbitrary and capricious standard of the Administrative Procedure Act and by constitutional protections of private property - the jurisdictional separations process could have the practical effect of capping the price for service $A$ below its stand-alone cost by virtue of the insufficient amount of common costs jurisdictionally allocated to that service. Meanwhile, the separations process could allocate to service $B$ a seemingly generous amount of common costs that would imply a price exceeding the stand-alone cost of $B$; yet, being granted the regulatory freedom to charge a price exceeding stand-alone cost would be worthless to the ILEC, for the market already would constrain the ILEC to win no sales at a price that exceeded the stand-alone cost of $B$. If such a jurisdictional separation were not accompanied by an independent cost recovery mechanism, the process of jurisdictional separations would

271 In re Jurisdictional Separations Reform and Referral to the Federal-State Joint Board, 12 F.C.C.R. 22,120, \ 19, at 22,131 (emphasis added) (1997) (Notice of Proposed Rulemaking) (hereinafter Separations Notice].

272 Cf. Smith v. Ill. Bell Tel. Co., 282 U.S. 133, 149 (1930) ("[P]roper regulation of rates can be had only by maintaining the limits of state and federal jurisdiction" to determine whether rates are confiscatory). 
become a shell game. ${ }^{273}$ As the name implies, common costs are common to the overall activities of the ILEC. The arbitrary assignment of $X$ percent of those common costs to services regulated at the state level and $Y$ percent to services regulated at the federal level does not alter in any way the essential commonality of those costs. Nor, in the event that confiscatory rates deny the ILEC full recovery of its common costs of supplying network access, should such a jurisdictional assignment of costs magically limit the states' liability to $X$ percent of the unrecovered common costs and the FCC's liability to $Y$ percent of the unrecovered common costs. The ILEC should not be understood to compromise its right to full recovery of its common costs of network access because state and federal regulators happen to choose one allocation formula instead of another.

Currently, however, the law is not so clear, and regulatory practice not so forthright, as this commonsense statement of first principles might suggest. The FCC, for example, regards the separations process as a safeguard against an ILEC's overrecovery of its costs: "One of the primary purposes of this process is to prevent ILECs from recovering the same costs in both the interstate and intrastate jurisdictions." ${ }^{274}$ But the FCC seems not to recognize that underrecovery of the common costs of network access is just as serious a threat to consumer welfare.

This current gulf between first principles and established law creates the potential for the process of jurisdictional separation to aid the CLECs' strategy of raising rivals' costs through mandatory structural separation. If jurisdictional separation of common costs has the effect of denying the ILEC full recovery of the common costs that it prudently incurred to supply access to the local telecommunications network, then the jurisdictional separations rules will discourage new investment by the ILEC in network assets that support economies of scope in the provision of local telecommunications and that, consequently, are subject to that separations process. Mandatory structural separation would predictably affect precisely these assets of the ILEC.

\section{Conclusion}

The current debate over mandatory structural separation is only the latest manifestation of the regulatory conflict that has existed between AT\&T and the regional Bell operating companies since long before passage of the Telecommunications Act of 1996-indeed nearly since the

273 For a discussion of alternative cost recovery mechanisms, see SIDAK \& SPULBER, supra note 156 , at $444-47$.

274 Separations Notice, supra note $271, \eta$ 3, at 22,122-23. 
effective date of the AT\&T divestiture on January 1, 1984. The calls for mandatory structural separation of the incumbent local exchange carriers sound like the controversy de jour. For decades, the ILECs have faced rate-of-return or price-cap regulation to prevent their exploitation of their dominant positions in local exchange telecommunications. Next, the Bell operating companies specifically were subjected to line-of-business restrictions to prevent their exploitation of their dominant positions in local exchange telecommunication. Then, the ILECs were subjected to mandatory unbundling of their network elements at regulated prices to prevent their exploitation of their dominant positions in local exchange telecommunications. Now, AT\&T and other CLECs insist that mandatory structural separation of the ILECs is essential to prevent their exploitation of their dominant positions in local exchange telecommunications. To paraphrase T.S. Eliot, the calls for mandatory structural separation of the ILECs "follow like a tedious argument of insidious intent." the number and variety of policy instruments that legislators and their expert regulators have used to pursue the common end of protecting consumers of telecommunications services, one must question, if we are to take the proponents of structural separation seriously, whether each of those means to date has been a colossal failure (in which case, so might also be mandatory structural separation). Alternatively, one must question whether the actual, unstated purpose of those policy instruments has been to pursue an entirely different objective of managing and handicapping competitive outcomes to the satisfaction of legislators, regulators, andmost importantly - interested companies (in which case, the imposition of mandatory structural separation would justify similar cynicism).

Mandatory structural separation is unnecessary because the putative benefits that it would produce are, in fact, nonexistent. Mandatory structural separation cannot be necessary to increase competition in local exchange services because regulators already (1) prohibit discrimination by means of more direct but less-intrusive behavioral policies and (2) regulate not only the ILEC's prices for end services sold to consumers, but also its prices for UNEs and wholesale services sold to CLECs. Given this multiple overlay of regulation, the ILECs surely cannot exercise market power in the sale of end services to consumers or in the sale of inputs to competitors. No malady exists for mandatory structural separation to cure. Mandatory structural separation, however, would clearly impose substantial costs on the ILECs. Because those costs are unnecessary to

275 T.S. Eliot, The Love Song of J. Alfred Prufrock, in THE WASTE LAND AND OTHER POEMS (1930). 
advance any public-interest objective, they are also social costs - a waste of economic resources.

At the same time, the debate over mandatory structural separation obscures three propositions that regulators, legislators, and courts cannot ignore if they are to protect the interests of consumers. First, the many failures of individual CLECs assuredly flow from defects in their own business strategies, management, and financing rather than from violations of antitrust law or the Telecommunications Act by the ILECs. Second, although many CLECs have failed since 1996, the CLEC industry has made substantial inroads into the market for local telecommunications, and, thus, CLECs as a group have, as the FCC has documented, captured a rapidly growing share of the local exchange market from the ILECs. Third, quite apart from its ostensible purposes, mandatory structural separation of the ILECs can facilitate a sophisticated and anticompetitive strategy of the large CLECs (including AT\&T) to raise the costs of their rivals, the ILECS.

In short, mandatory structural separation of the ILECs is a nonremedy for a non-problem. It would invite strategic abuse of the regulatory process and obscure the self-evident proposition that every footrace must have a winner and a loser. Regulators and legislators would better serve the public interest by rejecting calls to mandate structural separation of the ILECS. 
